\title{
Amyloid Precursor Proteins Interact with the Heterotrimeric G Protein Go in the Control of Neuronal Migration
}

\author{
Jenna M. Ramaker, ${ }^{1,2}$ Tracy L. Swanson, ${ }^{1}$ and Philip F. Copenhaver ${ }^{1,2}$ \\ ${ }^{1}$ Department of Cell and Developmental Biology and ${ }^{2}$ Neuroscience Graduate Program, Oregon Health and Science University, Portland, Oregon 97239
}

\begin{abstract}
Amyloid precursor protein (APP) belongs to a family of evolutionarily conserved transmembrane glycoproteins that has been proposed to regulate multiple aspects of cell motility in the nervous system. Although APP is best known as the source of $\beta$-amyloid fragments (A $\beta$ ) that accumulate in Alzheimer's disease, perturbations affecting normal APP signaling events may also contribute to disease progression. Previous in vitro studies showed that interactions between APP and the heterotrimeric G protein Go $\alpha$-regulated Go $\alpha$ activity and Go-dependent apoptotic responses, independent of A $\beta$. However, evidence for authentic APP-Go interactions within the healthy nervous system has been lacking. To address this issue, we have used a combination of in vitro and in vivo strategies to show that endogenously expressed APP family proteins colocalize with Go $\alpha$ in both insect and mammalian nervous systems, including human brain. Using biochemical, pharmacological, and Bimolecular Fluorescence Complementation assays, we have shown that insect APP (APPL) directly interacts with Go $\alpha$ in cell culture and at synaptic terminals within the insect brain, and that this interaction is regulated by Go $\alpha$ activity. We have also adapted a well characterized assay of neuronal migration in the hawkmoth Manduca to show that perturbations affecting APPL and Go $\alpha$ signaling induce the same unique pattern of ectopic, inappropriate growth and migration, analogous to defective migration patterns seen in mice lacking all APP family proteins. These results support the model that APP and its orthologs regulate conserved aspects of neuronal migration and outgrowth in the nervous system by functioning as unconventional Go $\alpha$-coupled receptors.
\end{abstract}

\section{Introduction}

Amyloid precursor protein (APP) is best known as the source of $\beta$-amyloid (A $\beta$ ) peptides that have been postulated to cause Alzheimer's disease (AD) (Hardy and Selkoe, 2002). However, therapeutic strategies targeting $\mathrm{A} \beta$ have been unsuccessful (Karran et al., 2011), suggesting that other APP-related processes may contribute to the disease (Mangialasche et al., 2010). APP is a member of an evolutionarily ancient family of type 1 glycoproteins that possess highly conserved extracellular and intracellular domains, indicating that they can participate in transmembrane

\footnotetext{
Received March 15, 2013; revised May 7, 2013; accepted May 14, 2013.

Author contributions: J.M.R. and P.F.C. designed research; J.M.R., T.L.S., and P.F.C. performed research; J.M.R. and P.F.C. analyzed data; J.M.R. and P.F.C. wrote the paper.

Support for this work was provided by National Institutes of Health (NIH) R01 AG025525 and R21 NS080036 (P.F.C.), and by a grant from the Oregon Partners for Alzheimer's Research to J.M.R., who is a Vertex Scholar. The Oregon Brain Bank is supported by the Layton Aging and Alzheimer's Disease Center, NIH P30 AG8017. Confocal imaging was supported by NIH P30 NS061800. We thank Drs. Doris Kretzschmar, David Morton, and Larry S. Sherman for critical input on this manuscript. We also thank Drs. Vivian Budnik, Michael Gorczyca, and Kalpana White for generously sharing their APPL antibodies, fly lines, and helpful suggestions. Primary cultures of embryonic rat hippocampal neurons were provided by Dr. Gary Banker and Ms. Barbara Smoody, Jungers Center, Oregon Health and Science University (OHSU), Portland, OR. Mouse brain samples were kindly provided by Dr. Joseph Quinn and Christopher Harris (Department of Neurology, Portland Veterans Administration Medical Center, and Layton Center for Aging and Alzheimer's Disease Research, $\mathrm{OHSU}$ ). Frozen samples of human brain tissue were made available by the Oregon Brain Bank (following established protocols), with the generous assistance of Dr. Randall L. Woltjer (Department of Pathology, OHSU). We thank Dr. Stephen Michnick (University of Montreal) for providing plasmids containing the coding domains for complementary portions of Venus Fluorescent Protein (Vn1 and Vn2). We Are grateful to Dr. Stefanie Kaech and Aurelie Snyder for assistance with the confocal imaging analysis that was performed in the Advanced Light Microscopy Core, Jungers Center, OHSU.

The authors declare no competing financial interests.

Correspondence should be addressed to Dr. Philip F. Copenhaver, Cell and Developmental Biology L-215; Oregon Health and Science University; 3181 SW Sam Jackson Park Road; Portland, 0R, 97239. E-mail: copenhav@ohsu.edu. DOI:10.1523/JNEUROSCI.1146-13.2013

Copyright $\odot 2013$ the authors $\quad 0270-6474 / 13 / 3310165-17 \$ 15.00 / 0$
}

signaling events (Turner et al., 2003; Gralle and Ferreira, 2007). Both full-length APP and its cleavage products have been ascribed multiple roles in neuronal motility (Perez et al., 1997; Sabo et al., 2003; Young-Pearse et al., 2008), including the control of neuronal migration in the developing brain (Herms et al., 2004; Young-Pearse et al., 2007; Rice et al., 2012). However, attempts to validate these functions in vivo have produced conflicting results, in part due to molecular redundancy with two closely related proteins (APLP1 and APLP2) and compensatory interactions by other guidance cues (Heber et al., 2000; Bergmans et al., 2010). Although APP may interact with a plethora of adapter and signaling proteins (Reinhard et al., 2005), the mechanisms by which APP and its orthologs regulate neuronal motility in the nervous system have remained elusive.

Intriguing studies have shown that APP interacts with the heterotrimeric $\mathrm{G}$ protein $\mathrm{Go} \alpha$, at least under some conditions. In artificial liposomes and extracted membranes, APP can regulate Go $\alpha$ activity (Nishimoto et al., 1993; Okamoto et al., 1995), while cells transfected with APP isoforms associated with familial AD (FAD) exhibit constitutive Go $\alpha$ activation and accelerated apoptosis (Okamoto et al., 1996; Yamatsuji et al., 1996). Notably, these effects were prevented by the Gi/o inhibitor pertussis toxin or by expressing APP isoforms lacking their putative Go-binding domain (Yamatsuji et al., 1996). Elevated G protein activity and decreased APP-Go $\alpha$ interactions have also been detected in brain samples from AD patients (Reis et al., 2007; Shaked et al., 2009), while cell culture studies suggest that $\mathrm{A} \beta$ peptides induce neurotoxic effects via the dysregulation of APP-Go $\alpha$ signaling (Sola Vigo et al., 2009). These results support the model that APP might function as an atypical Go-coupled receptor whose normal 
functions are disrupted in AD. However, a viable assay for investigating endogenous APP-Go $\alpha$ interactions in neurons has been lacking.

To address this issue, we have established the embryonic nervous system of Manduca sexta (hawkmoth) as a novel preparation for testing how APP family proteins control neuronal migration. As in other invertebrate models, Manduca express only one APP ortholog (APP-Like; APPL), and previous studies have shown that both APPL and Go $\alpha$ are robustly expressed by migratory neurons in this system (Horgan et al., 1995; Swanson et al., 2005). We have now used a combination of in vitro and in vivo assays to determine whether endogenously expressed APP family proteins interact with Go $\alpha$ in neurons from multiple species, whether this interaction is direct, and whether APPL-Go $\alpha$ signaling regulates neuronal migration within the developing nervous system.

\section{Materials and Methods}

Whole-mount immunostaining of staged embryos. Synchronous groups of embryos of either sex were collected from an in-house colony of $M$. sexta and staged according to a panel of external and internal developmental markers (Copenhaver and Taghert, 1989a,b). When reared at $25^{\circ} \mathrm{C}$, embryogenesis is complete in $100 \mathrm{~h}$, whereby $1 \%$ of development is equivalent to $1 \mathrm{~h}$ postfertilization (hpf). Embryos were collected at 55, 58, and $65 \mathrm{hpf}$ (before, during, and after enteric plexus (EP) cell migration) and dissected in defined saline ( $140 \mathrm{~mm} \mathrm{NaCl}, 5 \mathrm{~mm} \mathrm{KCl}, 28 \mathrm{~mm}$ glucose, 40 $\mathrm{mm} \mathrm{CaCl}_{2}$, and $5 \mathrm{~mm}$ HEPES, $\mathrm{pH}$ 7.4) to expose the enteric nervous system (ENS), as described previously (Horgan et al., 1995; Coate et al., 2007). For immunohistochemical analysis, embryos were filleted dorsally to expose the developing ENS and subsequently fixed in 4\% paraformaldehyde (PFA; Sigma-Aldrich) in PBS for $1 \mathrm{~h}$ at room temperature. After extensive rinsing in PBS plus $0.1 \%$ Triton X-100 (PBST), embryos were pre-incubated for $1 \mathrm{~h}$ in blocking solution (10\% normal horse serum plus $0.1 \%$ sodium azide in PBST). Embryos were then incubated in antibodies diluted in blocking solution with constant agitation for either $1 \mathrm{~h}$ at room temperature or overnight at $4^{\circ} \mathrm{C}$.

For immunostaining, antibodies were used at the following concentrations: anti-mouse Fasciclin II (Fas II; C3 monoclonal), 1:20,000 (Wright et al., 1999); affinity-purified anti-Go $\alpha, 1: 100$ (generated against amino acids 343-355 of Manduca Go $\alpha$; Horgan et al., 1995); and anticAPPL, 1:2500 (previously referred to as anti-msAPPL-cyt), generated against the sequence YENPTYKYFEVKE within the cytoplasmic domain of Manduca APPL (Swanson et al., 2005). We also generated an additional polyclonal antiserum (anti-nAPPL, \#21506; 1:5000) against a fusion protein derived from the E1 ectodomain region of Manduca APPL (amino acids 1-197). The specificity of this antiserum for APPL was validated in Western blots of Manduca and Drosophila lysates; by coimmunohistochemical staining with our other APPL antibodies; by preadsorption against the fusion protein (vs control fusion proteins); and by cross-immunoprecipitation with other anti-APPL antibodies (data not shown). Primary antibodies against Fas II and APPL were detected with fluorochrome-conjugated secondary antibodies diluted in blocking solution. Antibodies conjugated to Alexa Fluor 488, 568, or 647 (Invitrogen/Life Technologies) were used at a final concentration of 1:1000; antibodies conjugated to Cy3 and DyLight 549 (Jackson ImmunoResearch) were used at 1:400. Anti-Go $\alpha$ was detected with anti-guinea pig secondary antibodies coupled to horseradish peroxidase (HRP) and visualized using the tyramide signal amplification system (TSA Plus Fluorescence Kit; PerkinElmer), following the manufacturer's instructions. Whole-mount immunostained preparations were stored in Elvanol (Banker and Goslin, 1998) and imaged with an Olympus FluoView 300 laser scanning confocal head mounted on an Olympus BX51 microscope (located in the Live Cell Imaging Facility, Center for Research on Occupational and Environmental Toxicology, OHSU), or with an inverted Zeiss LSM710 confocal microscope (located in the Advanced Imaging Center of the Jungers Institute, OHSU). Maximum intensity projections of flattened $Z$-stack confocal images were generated using MetaMorph software. To illustrate the relationships between the EP cells and their muscle band pathways (Fig. 1), Fas II immunostaining in each panel was cropped at either the foregut (FG)/midgut (MG) boundary ( $55 \mathrm{hpf}$ ) or at positions adjacent to the most posterior neurons on each pathway (58-65 hpf). The cropped Fas II images were then montaged with the flattened $Z$-stack images of APPL immunostaining in the same preparations.

To examine the colocalization of mammalian APP with Go $\alpha$, primary cultures of embryonic rat hippocampal neurons (grown on coverslips) were provided by Dr. Gary Banker (OHSU; Dotti et al., 1988). Neurons were fixed with $4 \%$ PFA in PBS for 15 min at room temperature, permeabilized for $10 \mathrm{~min}$ with $0.1 \%$ PBST, and blocked for $15 \mathrm{~min}$ with $5 \%$ fish skin gelatin in PBST. The following primary antibodies were applied for $60 \mathrm{~min}$ at room temperature: anti-22C11 targeting amino acids $66-81$ of human APP (Millipore \#MAB348, 1:100); anti-pAPP, specific to pThr668 within amino acids 666-670 of human APP (Sigma-Aldrich \#SAB4300153; 1:200); and affinity-purified anti-Go $\alpha$, 1:300 (Horgan et al., 1995). Secondary antibodies conjugated to Alexa Fluor 488, 568, or 647 (Invitrogen/Life Technologies) were used at a final dilution of 1:1000. Coverslips were mounted in Elvanol and imaged as described above.

Coimmunoprecipitation and immunoblotting. Staged Manduca embryos (20 per reaction; dissected at $65 \mathrm{hpf}$ ) and adult Drosophila heads (20 per reaction) were collected on dry ice and homogenized in $1 \%$ Triton lysis buffer ( $1 \%$ Triton X-100, $150 \mathrm{~mm} \mathrm{NaCl}, 50 \mathrm{~mm}$ Tris, $\mathrm{pH} 8$ ) or $1 \% \mathrm{NP} 40$ lysis buffer ( $150 \mathrm{~mm} \mathrm{NaCl}, 50 \mathrm{~mm}$ Tris, $\mathrm{pH} 8)$. Aliquots of each lysate were centrifuged at $16,000 \mathrm{rpm}$ for $10 \mathrm{~min}$, and the supernatants were precleared with Protein A/G beads (Santa Cruz Biotechnology). The supernatants were then incubated with primary antibodies (described below) for $1-3 \mathrm{~h}$ at room temperature or overnight at $4^{\circ} \mathrm{C}$ and incubated with prewashed beads for $1 \mathrm{~h}$. The bead-bound antibody complexes were then pelleted by centrifugation. After washing in chilled lysis buffer, immunoprecipitated protein complexes were eluted by boiling the beads in SDS sample buffer for $1 \mathrm{~min}$ (Swanson et al., 2005). The samples were then separated on $10 \%$ or $4-12 \%$ Criterion polyacrylamide gels (Bio-Rad), transferred to nitrocellulose, and immunoblotted with antibodies diluted in Tris-buffered saline plus $0.1 \%$ Tween 20 (polysorbate) and 5\% Carnation dry milk.

For coimmunoprecipitations using mouse brain, frozen tissue samples were provided by Dr. Joseph Quinn and Christopher Harris (Department of Neurology, Portland Veterans Administration Medical Center, and Layton Center for Aging and Alzheimer's Disease Research, OHSU). Brains were divided in half under liquid nitrogen, extracted in NP40 lysis buffer, and immunoprecipitated by the methods described above. Alternatively, membranes were prepared from lysed mouse brain samples following the protocol described in (Hortsch, 1994). Briefly, tissue was homogenized in hypotonic saline (100 mM Tris- $\mathrm{HCl}, \mathrm{pH} 8.0 ; 1$ mM EDTA) and centrifuged at $100,000 \times g$ for $1 \mathrm{~h}$ at $4^{\circ} \mathrm{C}$. The pellets were then resuspended in NP40 lysis buffer, incubated with primary antibodies for $3 \mathrm{~h}$ at room temperature or overnight at $4^{\circ} \mathrm{C}$, and immunoprecipitated as described above. For coimmunoprecipitations using human brain tissue, frozen samples were made available from the Oregon Brain Bank (collected and distributed following established protocols), with the assistance of Dr. Randall L. Woltjer (Department of Pathology, OHSU). Approximately $90 \mathrm{mg}$ of tissue per reaction was homogenized with a Dounce homogenizer in $1 \mathrm{~mm}$ EDTA, $100 \mathrm{~mm} \mathrm{NaCl}, 50 \mathrm{~mm}$ Tris- $\mathrm{HCl}, \mathrm{pH} 8$ ), plus $1 \%$ Triton $\mathrm{X}-100$ (Roche) and $0.5 \%$ sodium cholate (Sigma-Aldrich). Undigested protein was then pelleted in a Beckman L7-55 ultracentrifuge for $1 \mathrm{~h}$ at $100,000 \times g$ at $4^{\circ} \mathrm{C}$, and the supernatants used for subsequent immunoprecipitation reactions as described by (Shaked et al., 2009). Samples were incubated with antibodies overnight at $4^{\circ} \mathrm{C}$ with continuous rocking and then immunoprecipitated, as described above.

The following antibodies were used to immunoprecipitate APPassociated proteins: for Manduca lysates, we used anti-cAPPL and antinAPPL-EX, previously referred to as anti-msAPPL-ect (generated against the sequence EDDDYTDADDSAWPRPES within the extracellular domain of Manduca APPL; Swanson et al., 2005). For Drosophila lysates, we used anti-cAPPL. For mouse lysates, we used anti-nAPP 
(Sigma-Aldrich \#8967, targeting amino acids 46-60 of human APP 695 ); anti-cAPP (Sigma-Aldrich A8717, targeting amino acids 676-695 of human $\mathrm{APP}_{695}$ ); and anti-APP ${ }_{668}$ (Sigma-Aldrich \#SAB4300464, targeting amino acids 666-670 of human $\left.\mathrm{APP}_{695}\right)$. For human brain lysates, we used anti-nAPP (Sigma-Aldrich \#8967). For each experiment, replicate lysates were immunoprecipitated with matched control immunoglobulins: purified IgY ( $7.5 \mu \mathrm{g}$, Aves \#N-1010) was used in experiments using chicken-derived antibodies; purified IgG (10-12 $\mu \mathrm{g}$; The Jackson Laboratory \#1-000-003) or normal rabbit serum (1-3 $\mu$ l) was used in experiments using rabbit-derived antibodies. The following antibodies were used to detect $G$ proteins that were coimmunoprecipitated with APP or APPL: anti-Go $\alpha$ (1:100-1:250; Horgan et al., 1995); anti-Gs $\alpha$ (1:1K) against a conserved sequence shared by Drosophila and mammalian Gs $\alpha$ (Santa Cruz Biotechnology \#sc-383); anti-Gi $\alpha$ (1:1000), targeting the conserved C-terminal sequence 327-355 (a gift from Dr. Michael Forte, OHSU; as described by Copenhaver et al., 1995); and anti-G $\beta \gamma(1: 75 ; \mathrm{BD}$ Transduction Laboratories). Secondary antibodies coupled to HRP were purchased from Jackson ImmunoResearch and used at 1:10K, and detected using standard chemiluminescent protocols (with either West Pico or West Femto substrates; ThermoFisher).

For coimmunoprecipitation experiments to test whether the Gobinding domain in APPL was required for APPL-Go $\alpha$ interactions in Drosophila, we used the following transgenic lines (provided by Dr. Vivian Budnik and Michael Gorczyca, University of Massachusetts Medical School, Worcester, MA): Appld a null mutation of the Appl gene (Luo et al., 1992); UAS-Appl $l^{s d}$, encoding an in-frame mutation that lacks amino acids 758-791 (and has the point mutations $\operatorname{Arg}_{795} \mathrm{Arg}_{796}-\mathrm{Leu}_{795} \mathrm{Ser}_{796}$ ), which is insensitive to secretase cleavage (secretase-deficient APPL; Luo et al., 1992); and UAS-Appl ${ }^{s d}{ }_{\Delta} \mathrm{Cg}$, secretase-deficient APPL that lacks amino acids $845-855$ within its Go domain (APPL ${ }^{\text {sd } \Delta} \mathrm{Cg}$; Torroja et al., 1999b). The UAS transgenes were crossed into Appl flies to test the interactions of each APPL variant in the absence of wild-type protein; $\mathrm{Appl}^{d}$ flies (lacking all APPL) served as a negative control. Expression of the transgenes was accomplished with the GAL4/UAS system (Brand and Perrimon, 1993), using the eye-specific GMR-GAL4 driver line (Bloomington Stock Center). For these assays, Drosophila lysates were immunoprecipitated with anti-Go $\alpha$ (EMD/Calbiochem \#371726) and immunoblotted with either anti-cAPPL (1:2500) or anti-G $\beta \gamma(1: 75)$, as described above.

Analysis of direct Go $\alpha$-APPL interactions by Bimolecular Fluorescence Complementation. Plasmids containing the coding domains for complementary portions of Venus Fluorescent Protein (Vn1 and $\mathrm{Vn} 2$ ) were provided by Dr. Stephen Michnick (University of Montreal, Montreal, Quebec, Canada) and used for a modified version of the Proteinfragment Complementation Assay (Remy et al., 2004). The APPL-Vn1 plasmid construct was generated in pcDNA3 (Invitrogen) by ligating the full-length coding domain of APPL in-frame with Vn1, consisting of amino acids 1-158 of Venus Fluorescent Protein plus a 10 aa glycine-rich linker domain (Benton et al., 2006; Mervine et al., 2006). The APPL $\Delta$ Go-Vnl construct was generated using PCR primers designed to omit the full Go-binding domain of Manduca APPL (amino acids 762-791; HAQGEVQVEQTGVVAPTPEERHVANMQING), identified by alignment with the Go-binding domain of human $\mathrm{APP}_{695}$ (His657-Lys676; as described by Nishimoto et al., 1993). Fusion constructs containing the coding domains of insect Go $\alpha$, Gi $\alpha$, and Gs $\alpha$ were ligated in-frame at their N termini with Vn2, consisting of amino acids 159-239 of Venus Fluorescent Protein plus a 10 aa glycine-rich linker region. For an in vitro analysis of Bimolecular Fluorescence Complementation (BiFC) induced by reassembly of Vn1and Vn2-tagged fusion proteins, COS7 cells were plated on poly-lysinecoated coverslips (at $20 \%$ density) and transiently transfected the following day with either $1000 \mathrm{ng}$ total plasmid DNA or $20 \mathrm{ng}$ plasmid DNA plus 980 ng pGEM-T helper plasmid, using TransIT-LT1 (Mirus Bio). After $18 \mathrm{~h}, 24 \mathrm{~h}$, or $48 \mathrm{~h}$, the cells were fixed for $10 \mathrm{~min}$ in $4 \%$ PFA, followed by incubation in blocking solution (PBS plus $10 \%$ normal horse serum) for $30 \mathrm{~min}$. Primary antibodies were diluted in blocking solution and applied to the cells for $1 \mathrm{~h}$ at room temperature. For this analysis, we labeled the cells with anti-nAPPL (1:1000), anti-Go $\alpha$ (1:100), and mouse anti-GFP (Invitrogen, A-11120), which recognizes the Vn2 fragment of the holoprotein. After rinsing with PBS, the cells were incubated with
Alexa Fluor 568- and Alexa Fluor 647-conjugated secondary antibodies (diluted 1:1000) for $30 \mathrm{~min}$, rinsed again, and mounted on glass slides with Elvanol for imaging with confocal microscopy. $Z$-stack images of each cell (five optical sections per stack) were acquired under linear parameters, using identical laser and acquisition settings. The stacked images were flattened in MetaMorph and adjusted for brightness and contrast, using identical settings for all cells imaged in an experiment. To quantify membrane-associated BiFC levels generated by different combinations of the $\mathrm{Vn} 1$ and $\mathrm{Vn} 2$ constructs, maximum intensity projections of each stacked image were generated in MetaMorph, and intensity values were determined for equivalent perimeter segments for each cell using Fiji software. Values were obtained independently for anti-APPL, anti-Go $\alpha$, and BiFC (visualized in different wavelengths). The mean values of average pixel intensities were then derived for replicate sets of cells (at least 20 cells per group), and used to evaluate statistical differences between the BiFC signals generated by the Venus-tagged proteins when expressed individually or in combination.

For BiFC analysis of APPL-Go $\alpha$ interactions in vivo, constructs containing the coding domains for Manduca APPL, APPL $\Delta$ Go, and Goo were cloned in-frame with Vn1 and Vn2, respectively. The constructs were then ligated into the pUASg (Appl) or pUAST (Go $\alpha)$ vector and used to transform Drosophila (BestGene). Transformant flies homozygous for UAS-APPL-Vn1, UAS-APPL $\Delta$ Go-Vn1, UAS-Vn2-Go $\alpha$, or recombined to express combinations of the constructs (UAS-APPL-Vn1 + Vn2-Go $\alpha$ or UAS-APPL $\Delta$ Go-Vn1 + Vn2-Go $\alpha$ ) were crossed with flies carrying the eye-specific GMR-GAL4 promoter construct (Brand and Perrimon, 1993). Mated flies were maintained at $28^{\circ} \mathrm{C}$, and third instar larvae were collected at various stages of development for imaging and analysis. Larval eye discs were isolated in PBS and immediately placed on ice. Discs were fixed for $10 \mathrm{~min}$ in PBS plus $4 \%$ PFA at $4^{\circ} \mathrm{C}$, then blocked for 30 min with $10 \%$ normal horse serum in PBS plus $0.1 \%$ Triton X-100. To detect the expression of either Vn1 or Vn2 fusion constructs, discs were immunostained with polyclonal GFP antibodies (Aves \#GFP1020 or Invitrogen \#A11122; 1:1000), which recognize both fragments of Venus fluorescent protein. To amplify BiFC signals specifically induced by the reassembly of Vn1 and Vn2, we used anti-GFP (Sigma-Aldrich \#G6539; 1:1000), which only labels the recombined protein. Discs were incubated in primary antibodies for $1.5 \mathrm{~h}$, then rinsed with PBS- $0.1 \%$ Triton X-100, and incubated with secondary antibodies (diluted in blocking solution) for $30 \mathrm{~min}$ at room temperature. DyLight 549 goatanti-chick antibodies (Jackson ImmunoResearch) were used at 1:200; Alexa Fluor-conjugated secondary antibodies (Invitrogen) were used at 1:1000. Whole discs were mounted in Elvanol, and flattened $Z$-stack images were obtained by confocal microscopy and ImageJ processing, using the same number of optical sections and laser settings for each disc.

Manipulations of endogenous $G$ protein activity. To test the role of $\mathrm{G}$ protein activity in regulating Go $\alpha$-APPL interactions, lysates were prepared from staged Manduca embryos or from GV1 cells (Hiruma and Riddiford, 2004), a Manduca cell line of ectodermal origin that endogenously expresses APPL and Go $\alpha$ (as well as other neuronal proteins; Coate et al., 2009). Cells and tissues were homogenized in either chilled NP40 buffer (1\%) or radioimmunoprecipitation assay buffer, and clarified by centrifugation at 13,000 rpm for $10 \mathrm{~min}$. The following reagents were then added to replicate aliquots of the lysates at the following final concentrations: GTP $\gamma$ S (Sigma), 0.05-10 $\mu \mathrm{m}$; GDP $\beta$ S (Sigma), 1-20 $\mu \mathrm{m}$; Mas7 (a mastoparan analog with enhanced activity; Enzo Life Sciences), 50-400 $\mu \mathrm{m}$; Mas17 (an inactive mastoparan analog; Enzo Life Sciences), $30 \mu \mathrm{m}$; and Pertussis Toxin A protomer (Enzo Life Sciences), $1-4 \mu \mathrm{g} / \mathrm{ml}$ plus $1 \mathrm{~mm} \mathrm{NAD}+$. After incubation at room temperature for $30 \mathrm{~min}$, the lysates were briefly centrifuged to remove cellular debris and analyzed by coimmunoprecipitation and immunoblotting, as described above. For analysis using the Odyssey Infrared Imaging System (LICOR), immunoblots were labeled with IRDye 680- and 800-conjugated secondary antibodies (from Rockland Immunochemicals and Invitrogen). Quantification of band intensities was performed using Odyssey software, and each experimental condition was normalized with respect to untreated control immunoprecipitations (run in parallel on the same immunoblots). Alternatively, immunoblots were processed using the chemiluminescent protocols described above; the blots were then imaged 
on $\mathrm{x}$-ray film with X-OMAT processing, scanned into TIFF files with Photoshop (Adobe), and relative pixel intensities were calculated for bands of interest using ImageJ (National Institutes of Health, Bethesda, MD). For each treatment condition, relative levels of Go $\alpha$ and APPL were normalized to levels detected in matched control samples (run on the same immunoblots) and imaged with identical parameters. Go $\alpha$ levels were then calculated as a ratio of Go $\alpha /$ APPL levels; each experiment was repeated at least three times. For statistical analysis, levels of immunoprecipitated Go $\alpha$ for each experimental condition were normalized to their respective untreated controls. Mean Go $\alpha$ levels for each treatment condition were then compared with matched untreated controls, using Student's two-tailed $t$ tests. Each experiment was repeated at least three times.

Embryonic culture and migration assays. Staged Manduca embryos were isolated at $52 \mathrm{hpf}$, shortly before the onset of EP cell migration. Embryos were dissected from their egg shells and extraembryonic membranes and placed in Sylgard-coated chambers filled with either culture medium (50\% Schneider's Drosophila medium, 40\% MEM with Hank's salts, 9.7\% heatinactivated normal horse serum, $0.2 \%$ 20-hydroxyecdysone, $0.1 \%$ insulin, and $0.01 \%$ penicillin-streptomycin (pen-strep), $\mathrm{pH} 7.4$ ); or defined saline (140 mm NaCl, $5 \mathrm{~mm} \mathrm{KCl,} 28 \mathrm{~mm}$ glucose, 5 mм HEPES, 4 mм CaCl$, 2,0.2 \%$ 20 -hydroxyecdysone, $0.1 \%$ insulin, and $0.01 \%$ pen-strep, $\mathrm{pH} 7.4$ ) (Horgan and Copenhaver, 1998). A small incision in the dorsal body wall between segments T2 and T3 (a position just anterior to the FG/MG boundary) was made to expose the EP on the developing gut. The premigratory EP cells were then directly treated with experimental reagents targeting APPL or Go $\alpha$. The incision was then gently closed with glass electrodes, and the embryos were allowed to develop in culture for another $12-24 \mathrm{~h}$ at $28^{\circ} \mathrm{C}$, spanning the time of normal EP cell migration and axon outgrowth. In experiments targeting subsequent aspects of axon elongation and terminal branch formation, embryos were opened in culture at $65 \mathrm{hpf}$ (at the end of the migratory period), treated with experimental reagents, and incubated for an additional $24 \mathrm{~h}$, spanning the normal period of synaptogenesis on the midgut musculature (Wright et al., 1998). Aluminum fluoride $\left(\mathrm{AlF}_{4-}\right)$ was prepared by diluting premixed solutions of $0.6 \mathrm{M} \mathrm{NaF}$ and $0.5 \mathrm{mM} \mathrm{AlCl}_{3}(1: 40)$ in culture medium to give a final concentration of $12.5 \mu \mathrm{M} \mathrm{AlF}_{4-}$; equivalent concentrations of $\mathrm{NaCl}$ premixed with $\mathrm{AlCl}_{3}$ served as controls (Horgan and Copenhaver, 1998). Pertussis toxin (PTX; intact molecule; Invitrogen) was pre-activated with $1 \mathrm{M}$ dithiothreitol and diluted in serum-free culture medium (Horgan et al., 1995). Treatment of the EP cells with anti-nAPPL antibodies (\#21506) was performed by diluting a purified IgG fraction of the antibody in culture medium; equivalent concentrations of control rabbit IgG (Jackson ImmunoResearch) were used as controls.

At the end of each experiment, embryos were dissected completely to expose the ENS, then fixed and immunostained with anti-Fas II to reveal the full extent of EP cell migration and outgrowth (Horgan et al., 1995; Wright et al., 1999). Anti-Fas II immunoreactivity was detected with biotinylated anti-mouse secondary antibodies (1:200) and the avidinbiotin-HRP protocol from Vector Laboratories (ABC kit). The distributions of postmigratory EP cells and their axons were analyzed using photomicrographic and camera lucida techniques. Ectopic outgrowth was quantified using a grid-based analysis of EP cell processes that had extended into each interband region of the midgut (normally inhibitory to the neurons); ectopic neurons were counted manually. To account for day-to-day variability in culture conditions, values obtained from each experimental preparation were normalized to mean values calculated from replicate sets of matched control preparations included with each experiment. Pairwise statistical differences between control and experimental groups were then calculated using Student's two-tailed $t$ tests.

Morpholino antisense oligonucleotides (morpholinos; Gene Tools) were designed against several regions of the mRNA sequence encoding Manduca APPL, and initially tested for their effectiveness and specificity in GV1 cells. Morpholinos were applied to cultured GV1 cells for $48 \mathrm{~h}$ (grown in GV1 medium: $3.32 \mathrm{~g}$ of lactalbumin hydrolysate and $20 \mathrm{ml}$ $50 \times$ Yeastolate per liter of Grace's medium, plus 10\% heat inactivated fetal bovine serum and 1\% pen-strep). The cells were then lysed in chilled NP40 lysis buffer, and residual APPL levels were analyzed by Western blotting methods; the expression of several control proteins (including
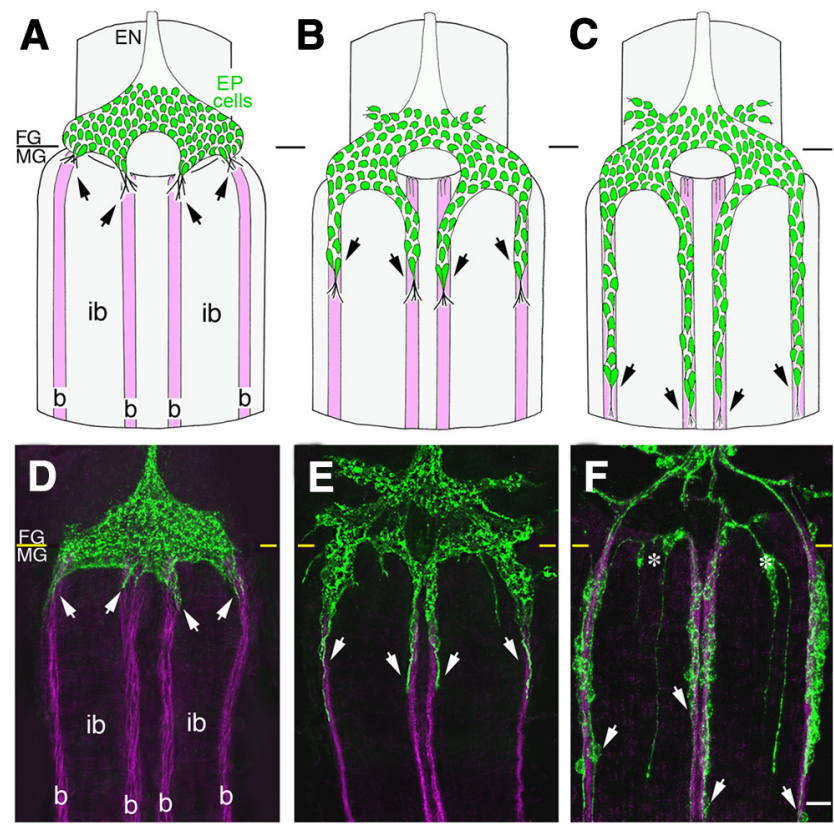

Figure 1. APPL is expressed by migrating EP cells and their motile processes. $A-C$, Schematic representation of the developmental sequence of EP cell migration (green) along the eight muscle band pathways (magenta) to form the enteric plexus of the ENS in Manduca (only the dorsal four muscle bands are shown). $\boldsymbol{D}-\boldsymbol{F}$, Montages of whole-mount preparations of filleted embryos that show the developing ENS from corresponding embryonic stages, immunostained for APPL (green) and Fas II (magenta; Fas II). (For these montaged images, Fas II staining was omitted from the EP cells to clearly show their alignment with the muscle bands; see Materials and Methods). $\boldsymbol{A}, \boldsymbol{D}$, By $55 \mathrm{hpf}$, the EP cells have spread bilaterally around the surface of the foregut, adjacent to the foregut/midgut (FG/MG) boundary; all of the neurons express APPL as they extend filopodia (arrows) preferentially onto the Fas II-positive muscle band pathways (b). $B, E$, By $58 \mathrm{hpf}$, subsets of EP cells have begun migrating along each muscle band pathway, while avoiding the adjacent interband regions (ib). APPL is strongly expressed throughout the motile cell bodies and within their leading processes that have extended along the bands (arrows). C, F, By $65 \mathrm{hpf}$, the EP cells have completed their migration (arrows) but will continue to grow axonal processes posteriorly along the band pathways for another $15 \mathrm{~h}$, before eventually innervating the lateral visceral musculature. Throughout this developmental sequence, the EP cells maintain robust levels of APPL expression (particularly in their most motile regions) and remain confined to the muscle band pathways, although a small number occasionally extend processes from the foregut-midgut boundary onto the interband regions (asterisks). EN, esophageal nerve of the $\mathrm{FG}$. White scale bar, $50 \mu \mathrm{m}$.

Fas II and tubulin) were visualized in the same samples to monitor for off-target effects of the morpholinos. The most effective APPL-specific morpholino (directed against a sequence spanning the initiation codon; CCGCGTTGCTTCCCACCAGCCC) was subsequently used to knock down APPL expression in cultured embryos. Morpholinos were diluted in defined saline $(1-50 \mu \mathrm{m})$ supplemented with $10 \%$ heat-inactivated horse serum, $0.5 \%$ pen-strep, $0.2 \% 20$-hydroxyecdysone, $0.1 \%$ insulin, and $0.2 \mathrm{M} \mathrm{L}$-glutamine. Embryos were opened in culture at $48 \mathrm{hpf}$, and the morpholinos were delivered into the EP cells with 0.6\% Endo-Porter (Coate et al., 2008). Matched sets of embryos were treated with standard control morpholinos (Gene Tools) or Endo-Porter alone. The embryos were then allowed to develop for an additional $24-48 \mathrm{~h}$ at $28^{\circ} \mathrm{C}$ before fixation and analysis, as described above. Matched sets of cultured preparations were also immunostained with anti-nAPPL to monitor the effectiveness of the morpholinos in inhibiting APPL expression.

\section{Results}

\section{Go $\alpha$ colocalizes with endogenous APPL and APP in} motile neurons

During formation of the ENS in Manduca, a population of $\sim 300$ neurons (EP cells) undergoes a stereotyped sequence of migration along preformed pathways to form a branching nerve plexus 


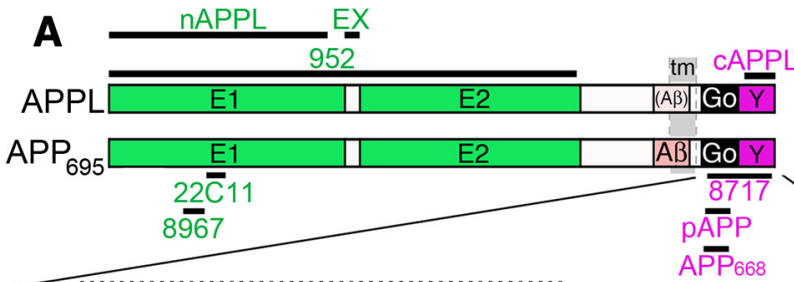

B hu ApP

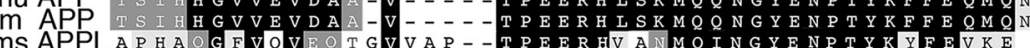
$\mathrm{dm} A P P L S$ P H A G F V Q VEOTGVVA P - TPE E R HV A M Q I N G Y E N P T Y K Y F E V K FEVDON-VT-- - T E E E T
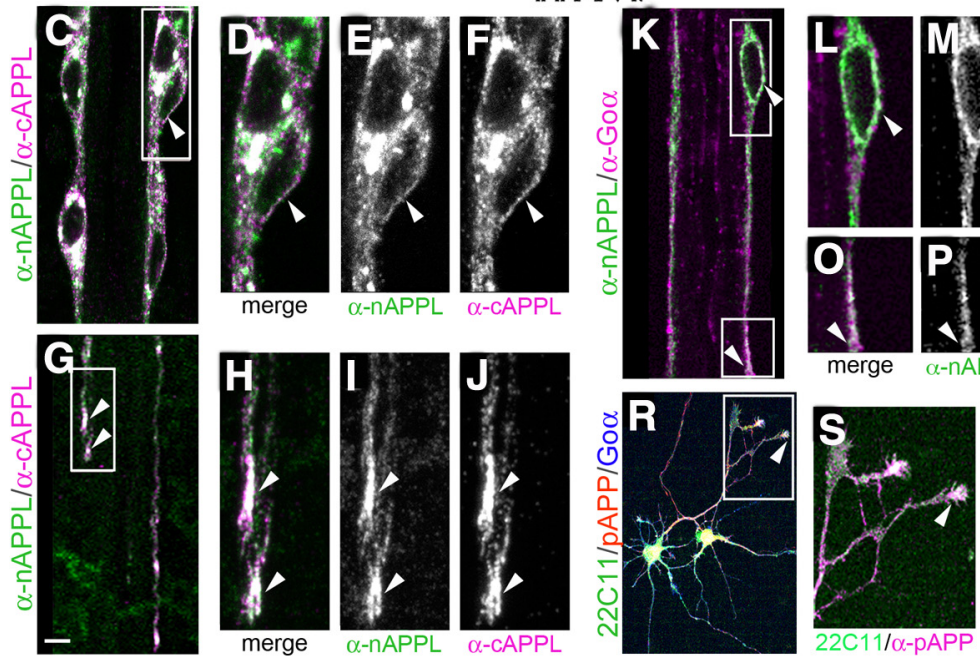

Figure 2. Go $\alpha$ colocalizes with APP family proteins in the motile regions of developing insect and mammalian neurons. $\boldsymbol{A}$ Schematic diagram of APPL and APP, indicating the conserved extracellular domains (E1 and E2), A $\beta$ domains, and the cytoplasmic Go-binding domain (Go) and internalization domain (Y). Transmembrane domains (tm) are shown in gray. Epitopes targeted by the different anti-APPL and APP antibodies used in this study are indicated by the labeled black lines. Antibodies targeting APP and APPL extracellular domains are labeled in green and antibodies targeting cytoplasmic domains are labeled in magenta. $\boldsymbol{B}$, Amino acid alignment of the conserved cytoplasmic domains in human (hu) APP, mouse (m) APP, Manduca (ms) APPL, and Drosophila (dm) APPL. Both the putative Go-binding domain (Go) and the internalization domain (Y) within the cytoplasmic (C-terminal) region of APP family proteins are highly conserved across species. Residues that are identical in at least three species are shaded in black; residues shared by two species are shaded in gray. The dotted black line indicates the putative Go-binding domain identified in APP 695 (Nishimoto et al., 1993; Okamoto et al., 1995). C, EP cells at 65 hpf immunostained with anti-nAPPL (green) and anti-cAPPL (magenta); the white box indicates the region highlighted in $\boldsymbol{D}-\boldsymbol{F}$. Individual channels in $\boldsymbol{E}$ (anti-nAPPL) and $\boldsymbol{F}$ (anti(APPL) are shown as monochrome images. Arrowheads indicate colocalized $\mathrm{N}$ - and $\mathrm{C}$-terminal immunostaining (which appears white in $\boldsymbol{D}$ ) at the plasma membrane, consistent with the presence of full-length transmembrane APPL. Images in $\boldsymbol{C} \boldsymbol{F}$ show compressed images of three optical sections acquired by confocal imaging. $\mathbf{G}$, Leading processes of EP cells on the dorsal muscle band pathways, immunostained with anti-nAPPL and anti-CAPPL antibodies; the white box indicates the region highlighted in $\boldsymbol{H}-\boldsymbol{J}$, which includes three to four fasciculated growth cones. Arrowheads indicate colocalized $\mathrm{N}$ - and $\mathrm{C}$-terminal immunostaining in the motile growth cones (white regions in $\boldsymbol{H}$ ); individual channels in $\boldsymbol{I}$ (anti-nAPPL) and $\boldsymbol{J}$ (anti-CAPPL) are shown as monochrome images. Images in $\mathbf{G}-\boldsymbol{J}$ show compressed images of 10 optical sections. $\boldsymbol{K}$, EP cells coimmunostained with anti-nAPPL (green) and anti-Go $\alpha$ (magenta); white boxes indicate regions highlighted in $\mathbf{L}-\mathbf{N}$ and $\mathbf{O} \mathbf{Q} \mathbf{Q}$. Arrowheads in $\mathbf{L} \mathbf{N}$ indicate the colocalization of APPL and $\mathrm{Go} \alpha$ at the plasma membrane of a migrating neuron; arrowheads in $\mathbf{0}-\mathbf{Q}$ indicate colocalization in the EP cell growth cone. Individual channels in $\boldsymbol{M}$ and $\boldsymbol{P}$ (anti-nAPPL) and $\boldsymbol{N}$ and $\boldsymbol{Q}$ (anti-Go $\alpha$ ) are shown as monochrome images. The images in $\boldsymbol{K}-\mathbf{Q}$ show single optical sections. $\boldsymbol{R}$, Rat hippocampal neurons immunostained with antibodies against $\mathrm{N}$-terminal APP (green, 22C11), C-terminal APP (red, pAPP), and Go $\alpha$ (blue); the white box indicates the highlighted region shown in $\mathbf{S}-\boldsymbol{T}$. S Enlarged view of colocalized N-APP (green) and C-APP (magenta) immunostaining in the neuronal growth cones, indicating the presence of transmembrane APP. $I$, Corresponding image of anti-Go $\alpha$ immunostaining (shown in monochrome), consistent with the colocalization of $G 0 \alpha$ with full-length APP in mammalian growth cones. Images $\boldsymbol{R}-\boldsymbol{T}$ show a compressed image of 10 optical sections. Scale bars: (in $\boldsymbol{C}, \boldsymbol{G}, \boldsymbol{K}) 7 \mu \mathrm{m}$; (in $\boldsymbol{D}-\boldsymbol{F}, \boldsymbol{H}-\boldsymbol{J}, \boldsymbol{L}-\mathbf{Q}) 3 \mu \mathrm{m}$; (in $\boldsymbol{R}$ ), $50 \mu \mathrm{m}$; (in $\mathbf{S}, \boldsymbol{T}) 25 \mu \mathrm{m}$.

(the EP), which spans the FG/MG boundary (Fig. 1A-C). After delaminating from a neurogenic placode in the FG epithelium (Copenhaver and Taghert, 1990), the EP cells first spread bilaterally around the FG (from 40 to $55 \mathrm{hpf}$ ). During this phase of migration (Fig. 1A; $52 \mathrm{hpf}$ ) approximately equal subsets of neurons align with one of the eight longitudinal muscle bands that have recently differentiated on the MG surface (Fig. $1 A$, b; only the four dorsal bands are shown). From 55 to 65 hpf (Fig. 1B; 58
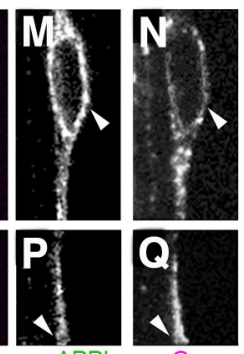

hpf), the neurons migrate in a chain-like manner along each of the muscle bands while avoiding adjacent interband regions (Fig. 1A, ib). From 65 to 75 hpf (Fig. 1C; $65 \mathrm{hpf}$ ), the neurons continue to elaborate long axons posteriorly along the MG (Copenhaver and Taghert, 1989a,b). During this process, EP cells actively extend and retract filopodia onto the band and interband muscles but remain aligned with their selected band pathways. Only once migration and axon outgrowth are complete do the neurons eventually sprout lateral branches that innervate the adjacent interband musculature (from 80 to 100 hpf). However, a small number of EP cells also normally extend processes onto the interband regions near the FG/MG boundary (Fig. $1 F$, asterisks; Copenhaver and Taghert, 1989b).

In previous work, we showed that a combination of permissive and repulsive guidance factors regulate the guidance of the EP cells along the muscle bands. The Ig-CAM Fas II (the insect ortholog of NCAM and OCAM) is expressed by both the EP cells and the muscle band cells, and homophilic signaling interactions mediated by Fas II play an essential role in promoting migration along these pathways (Copenhaver et al., 1996; Wright et al., 1999). (For clarity, the montages in Fig. 1, $D-F$, include Fas II immunostaining only in the muscle bands; see Materials and Methods). In addition, we recently showed that the migratory EP cells express APPL (Fig. 1D-F; green), coincident with their expression of Go $\alpha$ (Horgan et al., 1995; Swanson et al., 2005). Given the in vitro evidence that APP can interact with Go $\alpha$ (Nishimoto et al., 1993) and our previous data showing that Go $\alpha$-dependent signaling restricts the extent of EP cell migration (Horgan and Copenhaver, 1998), we investigated whether APPL might function as a transmembrane receptor that functionally interacts with $\operatorname{Go} \alpha$ in these migratory neurons.

Past studies have shown that insect APPL contains all of the key structural features that typify APP family proteins in other species (Fig. 2A), including conserved E1 and E2 extracellular domains that may interact with potential ligands (Luo et al., 1990; Swanson et al., 2005) and an $\mathrm{A} \beta$ domain that has neurotoxic effects when overexpressed as a cleavage fragment (Carmine-Simmen et al., 2009). In addition, the cytoplasmic domain of Manduca APPL shares strong similarity with equivalent domains in other APP-related proteins (Fig. $2 B$ ), including $88 \%$ sequence identity with Drosophila APPL and $77 \%$ identity with human $\mathrm{APP}_{695}$ (Swanson et al., 2005). Of particular note is the TPEER region within the putative Go-binding domain ("Go"; Nishimoto et al., 1993) and the NPXY phospho- 
tyrosine binding domain (Chen et al., 1990; Hoe and Rebeck, 2008; "Y") that are 100\% identical between Manduca and mammalian APP family proteins, suggesting that these domains regulate conserved signaling functions. As with human $\mathrm{APP}_{695}, \mathrm{APPL}$ undergoes a dynamic sequence of secretase-dependent cleavage to produce soluble ectodomain fragments, C-terminal fragments (CTFs), and APP intracellular domains (AICDs) (CarmineSimmen et al., 2009; Bolkan et al., 2012; J.M. Ramaker, T.L. Swanson, and P.F. Copenhaver, unpublished observations), each of which might affect different aspects of cell motility (Turner et al., 2003; Gralle and Ferreira, 2007). To investigate whether APPL can act as a Go $\alpha$-associated receptor in migratory neurons, we first examined whether APPL colocalized with Go $\alpha$ at the plasma membrane of the EP cells, consistent with a potential role in signal transduction.

For the current analysis, we used a panel of well characterized antibodies against the extracellular and intracellular domains of APP and APPL (Fig. 2A), including antibodies targeting conserved residues within the putative Go-binding domain. Double immunostaining the developing ENS with anti-nAPPL (against the N-terminal extracellular domain; green) and anti-cAPPL (against the C-terminal intracellular domain; magenta) verified the presence of the full-length holoprotein at the plasma membrane of migrating neurons (Fig. $2 C-F$, arrowheads) and their leading processes (Fig $2 G-J$, arrowheads). Also notable in these preparations was the abundance of additional APPL within large perinuclear vesicles, as well as smaller vesicle populations containing either $\mathrm{N}$-terminal (green) or $\mathrm{C}$-terminal fragments (magenta) of the holoprotein (Fig. $2 C-F$ ). We also found that the subcellular distributions of APPL and its fragments were markedly altered during periods of active migration and outgrowth, during which transmembrane APPL accumulated in regions of active growth (as manifested by the colocalization of $\mathrm{N}$ - and $\mathrm{C}$-terminal epitopes at the membrane). These observations support our previous evidence that APPL undergoes a dynamic sequence of trafficking, processing, and post-translational modifications that correlate with specific phases of EP cell differentiation (Swanson et al., 2005). They also are consistent with recent studies on APP trafficking in neuroblastoma cells (Muresan et al., 2009), suggesting that much of the newly synthesized holoprotein may be proteolytically cleaved and sorted to distinct compartments before their transport out of the cell body. This process may therefore help regulate the bioavailability of APPL as a transmembrane receptor during phases of active motility (J.M. Ramaker, T.L. Swanson, and P.F. Copenhaver, unpublished observations). To determine whether membrane-associated APPL colocalized with Go $\alpha$ in the EP cells, embryos were coimmunostained with antibodies against anti-nAPPL (green) and anti-Go $\alpha$ (magenta). As shown in Figure 2, $K-N$, robust colocalization was detected at the plasma membrane of the migratory neurons (arrowheads) and within their leading processes (Fig. 2O-Q, arrowheads). Surface labeling of unpermeabilized embryos with antinAPPL and subsequent permeabilization and staining for Go $\alpha$ verified that Go $\alpha$ colocalizes with cell-surface APPL in the EP cells (data not shown). To examine the relationship between APP and Go $\alpha$ expression in developing mammalian neurons, embryonic rat hippocampal neurons were isolated and fixed after $5 \mathrm{~d}$ in primary culture. The neurons were then triple immunostained with antibodies specific to the extracellular domain (green) and cytoplasmic domain of APP (red/magenta), as well as for Go $\alpha$ (blue/gray scale; Fig. $2 R-T$ ). As seen for APPL in the EP cells, full-length APP was found to be abundantly expressed within the growth cones of rat hippocampal neurons, where it colocalized with Go $\alpha$ (yellow/white regions, Fig. 2R-T). These results indicate that transmembrane forms of APP family proteins are closely associated with endogenously expressed Go $\alpha$ in developing neurons, particularly within regions of active growth and motility, and that this association is conserved in both invertebrate and vertebrate preparations.

\section{Both APPL and APP endogenously interact with Go $\alpha$}

In previous investigations, coimmunoprecipitation assays were used to show that both human APP and insect APPL can interact with Go $\alpha$ (Brouillet et al., 1999; Swanson et al., 2005; Shaked et al., 2009), but these studies did not determine whether Go $\alpha$ interacts specifically with full-length APP family proteins or with their C-terminal cleavage products (CTFs and AICDs). Another recent study showed that epitope-tagged CTFs of APP could interact with a different heterotrimeric $\mathrm{G}$ protein $(\mathrm{Gs} \alpha$ ) when overexpressed in cell culture (Deyts et al., 2012). Given that APP contains a conserved BBXXB domain, which in other receptor classes can promote binding to the $\alpha$-subunits of several different G proteins (Okamoto et al., 1990; Wu et al., 1995; Timossi et al., 2004), these results suggest that APP might function as a promiscuous $\mathrm{G}$ protein-associated receptor (Deyts et al., 2012).

To address this issue, we immunoprecipitated APPL from Manduca embryonic lysates with antibodies specific to both the $\mathrm{N}$ - and C-terminal domains of the holoprotein, and probed the resultant immunoblots with antibodies against different G protein subunits (Fig. 3A). As shown in Figure 3, $B$ and $C$, endogenously expressed Go $\alpha$ could be readily coimmunoprecipitated with both $\mathrm{N}$-terminal- and C-terminal-specific APPL antibodies, but not with matched control immunoglobulins (IgG and IgY, respectively). In contrast, APPL did not coimmunoprecipitate with either Gi $\alpha$ or Gs $\alpha$ (Fig. 3D,E), despite the robust expression of these $\mathrm{G}$ proteins in the embryonic nervous system (Copenhaver et al., 1995). Since APPL expression in insects is restricted to neurons (Martin-Morris and White, 1990), these results indicate that full-length APPL selectively interacts with endogenously expressed Go $\alpha$ but not other G proteins within the developing insect nervous system.

Previous experiments in Drosophila have shown that flies lacking APPL $\left(A p p l^{d}\right)$ exhibit defects in synaptic differentiation and aberrant adult behavior (Luo et al., 1992; Torroja et al., 1999a), supporting a role for APPL in regulating neuronal growth and target innervation. To complement our studies of APPL-Go $\alpha$ interactions in Manduca, we used fly head lysates to show that Drosophila Go $\alpha$ could be coimmunoprecipitated with anticAPPL antibodies from wild-type controls but not $A p p l^{d}$ flies (Fig. $3 F$ ), although both fly strains express equivalent levels of Go $\alpha$ (Fig. 3F, input). As noted above, Nishimoto et al. (1993) identified a candidate Go-binding domain within the cytoplasmic domain of human $\mathrm{APP}_{695}\left(\mathrm{His}_{657}-\mathrm{Lys}_{676}\right)$ that was required for APP-Go $\alpha$ interactions in reconstituted liposomes (Okamoto et al., 1995). To determine whether the conserved Go-binding domain is required for APPL-Go $\alpha$ interactions in the insect nervous system, we used transgenic fly lines expressing modified forms of APPL in the absence of wild-type protein. APPL ${ }^{\text {sd }}$ lacks the proteolytic cleavage site in APPL (amino acids 758-791) and consequently is expressed only as a transmembrane protein; $\mathrm{APPL}^{\text {sd }} \Delta \mathrm{Cg}$ also lacks a portion of the putative Go-protein binding site (amino acids 845-855; Torroja et al., 1999b). Using the GMR promoter, UAS constructs of each isoform were expressed in the eyes of $A p p l^{d}$ flies, and head lysates were immunoprecipitated with anti-Go $\alpha$. Blotting for $\alpha$-cAPPL revealed that Go $\alpha$ interacts with $\mathrm{APPL}^{\text {sd }}$ but not $\mathrm{APPL}^{\mathrm{sd}} \Delta \mathrm{Cg}$ (Fig. $3 G$ ), although 


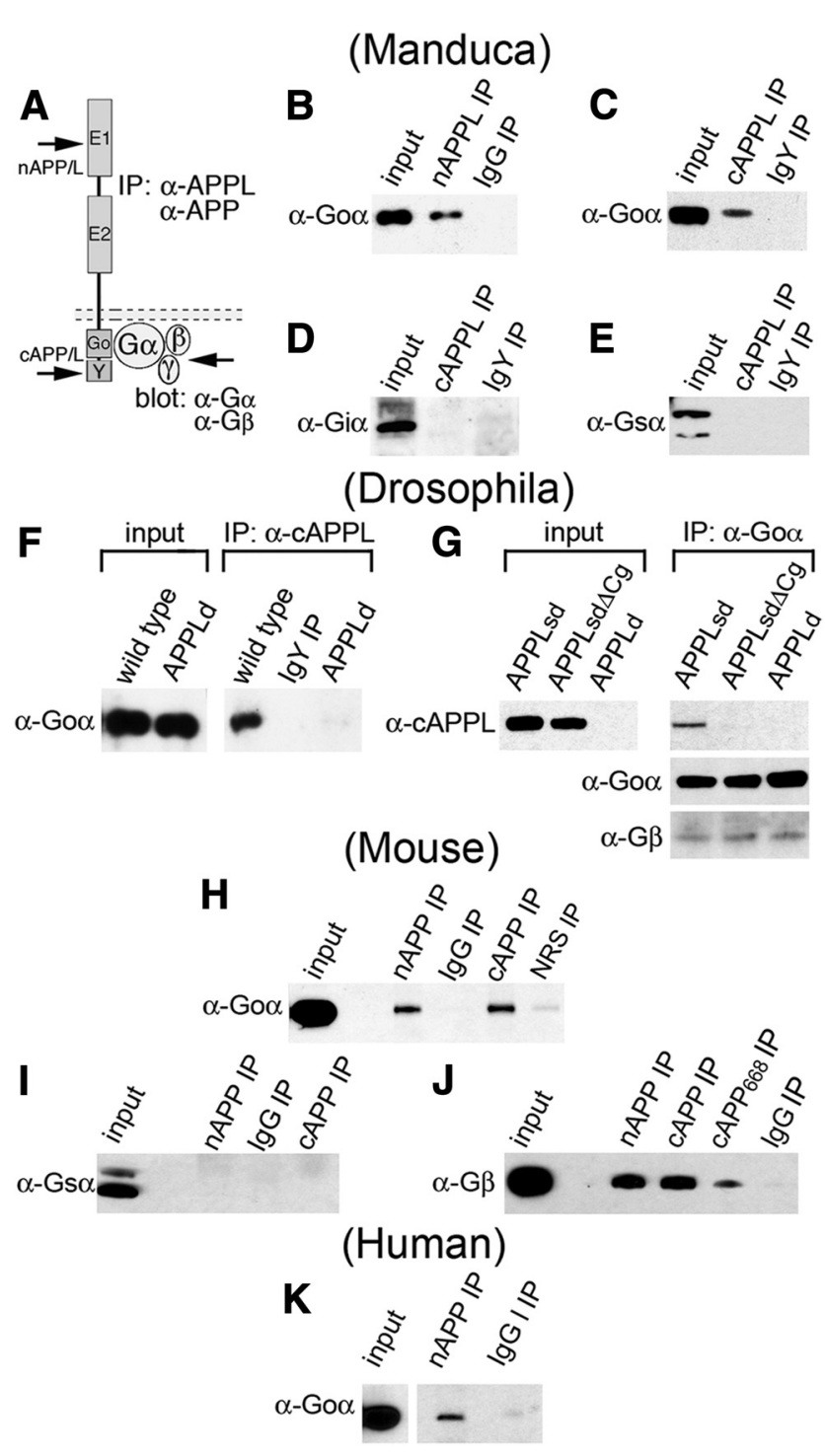

Figure 3. Go $\alpha$ interacts with transmembrane APPL and APP in the nervous system. $\boldsymbol{A}$, Schematic of the experimental protocol: tissue lysates were immunoprecipitated with antibodies specific for either the $\mathrm{N}$ - or C-terminal domains of APPL and APP, then immunoblotted with antibodies specific for different $G$ protein subunits. $\boldsymbol{B}-\boldsymbol{E}$, Western blots of Manduca embryonic lysates immunoprecipitated with anti-nAPPL or anti-CAPPL and immunoblotted with antibodies against different $\mathrm{G} \alpha$-subunits. $\boldsymbol{B}$, Embryonic lysate immunoprecipitated with anti-nAPPL and immunoblotted with anti-Go $\alpha$. Input lane shows endogenous Go $\alpha$ levels in the lysates before immunoprecipitation; IgG IP shows a matched negative control immunoprecipitation. $C_{\text {, }}$ Embryonic lysate immunoprecipitated with anti-CAPPL and immunoblotted with anti-Go $\alpha$. Input lane shows endogenous Go $\alpha$ levels in the lysates; IgY IP shows a matched negative control immunoprecipitation. The size of Manduca $\mathrm{Go} \alpha$ is $41 \mathrm{kDa}$. $\boldsymbol{D}-\boldsymbol{E}$, Western blots of Manduca embryonic lysates immunoprecipitated with anti-cAPPL and immunoblotted for either $\mathrm{Gi} \alpha(\boldsymbol{D})$ or $\mathrm{Gs} \alpha(\boldsymbol{E})$. Input lanes show endogenous $\mathrm{Gi} \alpha$ and $\mathrm{G} s \alpha$ levels in the lysates before immunoprecipitation. Neither $\mathrm{Gi} \alpha$ nor Gs $\alpha$ coimmunoprecipitate with anti-CAPPL or with control IgY. The size of $\mathrm{Gi} \alpha$ is $\sim 41 \mathrm{kDa}$; $\mathrm{Gs} \alpha$ is detected as a doublet at 48 and $52 \mathrm{kDa}$ (Copenhaver et al., 1995). F-G, Western blots of immunoprecipitated Drosophila head lysates. F, Drosophila head lysates from wild-type and $A P P L^{d}$ flies (which lack APPL expression) immunoprecipitated with anti-CAPPL and immunoblotted with anti-Go $\alpha$. Inputs show equivalent levels of endogenous $G_{0} \alpha$ in both fly lines. Go $\alpha$ was coimmunoprecipitated with anti-CAPPL antibodies from wild-type lysates but not with control lgY, nor from $A P P L^{d}$ lysates. $\mathbf{G}$, Western blot of lysates from $A_{p p l^{d}}$ flies overexpressing mutant forms of APPL under the control of the GMR promoter. App $P^{\text {sd }}$ flies ("secretion-deficient") express a transmembrane form of APPL lacking the juxtamembrane domain that is normally cleaved by secretases; $\mathrm{Appl}^{\mathrm{sd}}{ }_{\Delta}^{\mathrm{Cg}}$ flies express secretiondeficient transmembrane APPL, which also lacks the putative Go-binding domain. Fly head lysates were immunoprecipitated with anti-Gi/o $\alpha$ and immunoblotted with anti-CAPPL (135 $\mathrm{kDa}$ ). Input lanes show abundant expression levels of $A P P L^{\text {sd }}$ and $A P P L{ }^{s d} \Delta C$; no APPL-related both constructs were expressed at similar levels (Fig. 3G, input). $A p p l^{d}$ fly head lysates were used as a negative control. Probing the immunoprecipitates for Go $\alpha$ and $\mathrm{G} \beta$ verified that both subunits were abundantly expressed in all of the fly lines used for this analysis (Fig. 3G, IP). These results demonstrate that Go $\alpha$ interacts with transmembrane forms of APPL, consistent with its role as a Go $\alpha$-associated receptor, and that the conserved Go-binding domain within APPL is necessary for its interactions with Go $\alpha$ in vivo.

We also investigated whether endogenously expressed Go $\alpha$ interacts with full-length APP in the mammalian nervous system. Using similar methods, we found that Go $\alpha$ could be readily coimmunoprecipitated with both nAPP- and cAPP-specific antibodies from lysates prepared from cortical and hippocampal regions of adult mouse brain, compared with control IgG and normal rabbit serum (Fig. $3 H$ ), supporting the model that Go $\alpha$ interacts with full-length APP in neurons. In contrast, none of the APP-specific antibodies that we tested were found to coimmunoprecipitate Gs $\alpha$ (Fig. 3I), suggesting that Gs $\alpha$ does not normally interact with full-length APP or its C-terminal cleavage products in the brain. Whether elevated expression of APP or its fragments can promote this interaction under pathological conditions remains to be determined.

If APP and its orthologs function as authentic Go $\alpha$-coupled receptors, they would be expected to interact with heterotrimeric Go $(\alpha \beta \gamma)$ complexes in their inactive state (Bourne et al., 1991; Galés et al., 2006), whereas activation of APP signaling should induce their dissociation. Conversely, if APP and APPL function as downstream targets for activated Go $\alpha$, we would not expect them to associate with the $\alpha \beta \gamma$ trimer. As shown in Figure 3J, antibodies against both the $\mathrm{N}$ - and C-terminal domains of APP coimmunoprecipitated $\mathrm{G} \beta$-subunits as well as Go $\alpha$, similar to previous reports using extracted membrane preparations (Nishimoto et al., 1993). Last, based on recent studies suggesting that APP-Go $\alpha$ interactions might be perturbed in AD patients (Shaked et al., 2009), we also used human brain lysates prepared from the cortical regions of healthy control subjects (provided by the Oregon Brain Bank) to show that anti-nAPP antibodies also coimmunoprecipitated human Go $\alpha$, compared with the low background levels of Go $\alpha$ immunoprecipitated by control IgG (Fig. $3 K$ ). In combination, these results indicate that both insect

$\leftarrow$

proteins were detected in APPL ${ }^{\text {d flies. APPL }}{ }^{\text {sd }}$ but not APPL ${ }^{\text {sd }} \Delta$ Cg coimmunoprecipitated with Go $\alpha$, indicating that the Go domain is necessary for APPL-Go $\alpha$ interactions in vivo. Appl ${ }^{d}$ flies served as the negative control. Probing for $\alpha$-Go $\alpha$ verified that abundant levels of Go $\alpha$ were immunoprecipitated from each of the fly lines. Similar levels of $G \beta$ also coimmunoprecipitated with $\mathrm{Gi} / 0$ in all three fly lines, indicating equivalent expression of the heterotrimeric $G$ protein complexes. The size of fly $\mathrm{G} \beta$ is $\sim 37 \mathrm{kDa}$. $\boldsymbol{H} \boldsymbol{- J}$, Western blot of mouse brain lysates immunoprecipitated with N-terminal- or C-terminal-specific APP antibodies and immunoblotted with antibodies targeting different $\mathrm{G}$ protein subunits. $\boldsymbol{H}$, Immunoprecipitated mouse brain lysates labeled with anti-Go $\alpha$. Input shows endogenous $G_{0} \alpha$ levels in the lysate before immunoprecipitation. Lane 2: Go $\alpha$ coimmunoprecipitated with anti-nAPP. Lane 3: IgG = matched negative control immunoprecipitation. Lane 4: Go $\alpha$ also coimmunoprecipitated with anti-cAPP (8717; Fig. 2). Lane5: Matched negative control immunoprecipitation with normal rabbit serum (NRS).I, Immunoprecipitated mouse brain lysates immunoblotted for Gs $\alpha$. Input shows endogenous Gs $\alpha$ levels in the lysate before immunoprecipitation. Lanes 2-4 show that Gs $\alpha$ did not coimmunoprecipitate with anti-nAPP, control IgG, nor anti-CAPP. J, Mouse brain lysates immunoprecipitated with $\mathrm{N}$-terminal- or C-terminal-specific APP antibodies and immunoblotted with $\alpha-G \beta$. Input shows $G \beta$ levels in the lysates before immunoprecipitation. Lanes $2-4: G \beta$ coimmunoprecipitated with both anti-nAPP and anti-CAPP antibodies (8717 and (APP ${ }_{668}$ ). Lane 5: IgG-negative control immunoprecipitation. $\boldsymbol{K}$, Immunoprecipitated human brain lysates immunoblotted for Go $\alpha$. Input shows endogenous Go $\alpha$ levels in the lysate before immunoprecipitation. Go $\alpha$ was coimmunoprecipitated with anti-nAPP but not with control lgG. 

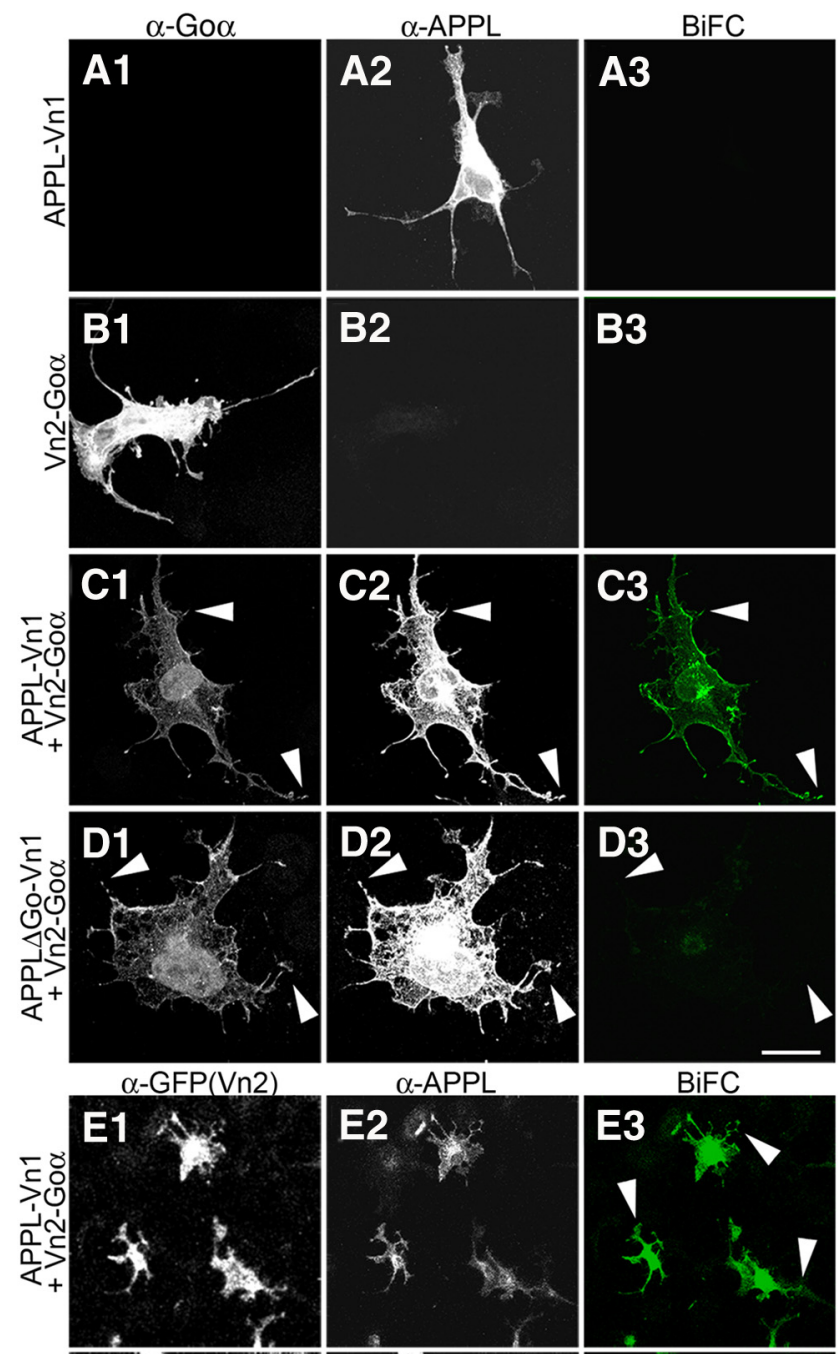

$\alpha-\mathrm{APPL}$
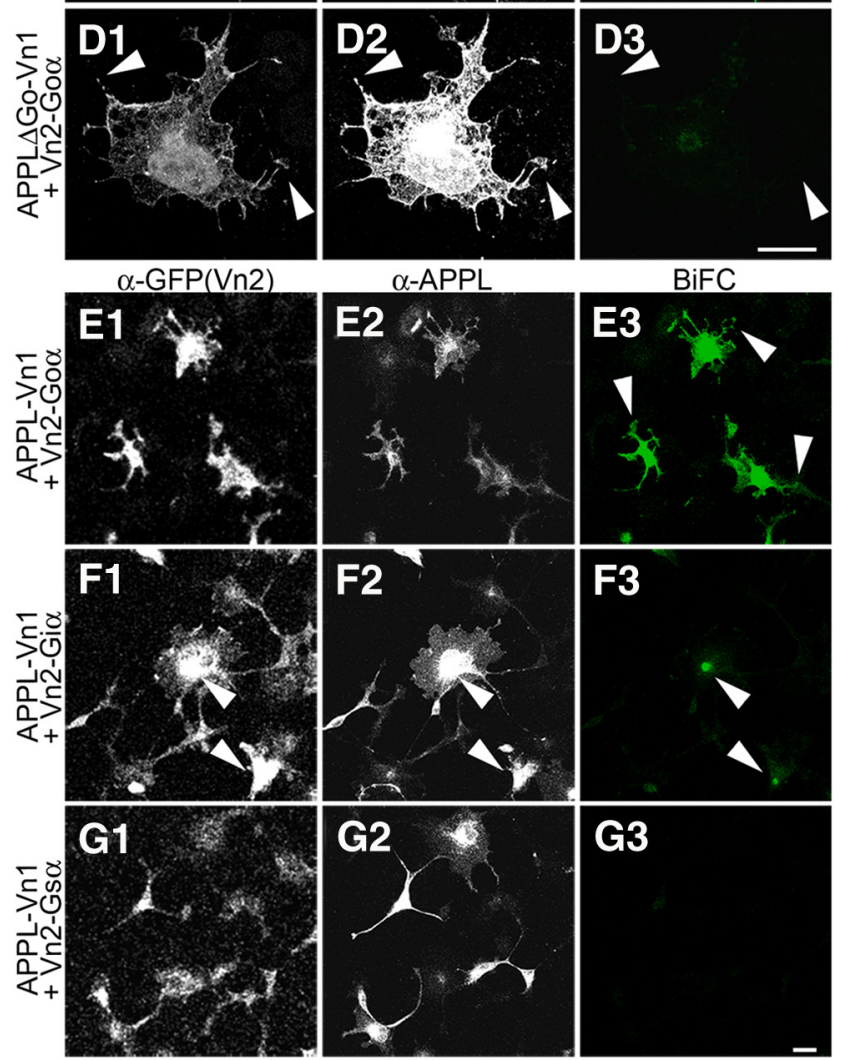

Figure 4. APPL and Go $\alpha$ directly interact in cell culture. $A-D$, Representative images of COS7 cells at $18-24 \mathrm{~h}$ post-transfection, immunostained with anti-Go $\alpha$ (left columns) and antiAPPL (middle columns) to detect constructs of interest. Right-hand columns show green fluorescent $B i F C$ signals that were produced by direct interactions between $\mathrm{Vn} 1$ - and $\mathrm{Vn2}$-tagged fusion proteins. $\boldsymbol{A}, \boldsymbol{B}$, Cell transfected with either APPL-Vn1 alone $\left(\boldsymbol{A}_{3}\right)$ or Vn2-Go $\alpha$ alone $\left(\boldsymbol{B}_{3}\right)$ did not emit detectable BiFC signals. $\boldsymbol{C}$, Cell cotransfected with both APPL-Vn1 and Vn2-Go $\alpha$ exhibited BiFC signals at the plasma membrane and throughout growing processes ( $\boldsymbol{C}_{\boldsymbol{3}}$, arrowheads). $\boldsymbol{D}$, Cell cotransfected with $\mathrm{Vn} 2-\mathrm{G}_{0} \alpha$ and APPL $\Delta \mathrm{G}_{0}-\mathrm{Vn} 1$ (APPL lacking the putative Go-binding domain; amino acids 762-791) produced only minimal BiFC signals that were restricted to the Golgi/ER regions. No detectable BiFC signals were present at the plasma membrane or growing processes of the cell $\left(\boldsymbol{D}_{3}\right.$, arrowheads), despite the expression of both constructs in these regions $\left(\boldsymbol{D}_{1}, \boldsymbol{D}_{2}\right)$. $\boldsymbol{E}-\mathbf{G}$, Lower magnification images of COS7 cells cotransfected with APPL-Vn1 plus equivalent levels of different $V_{n} 2$-tagged $G \alpha$ subunits. Forty-eight hours post-transfection, cells were coimmunostained with a Vn2-specific anti-GFP antibody
APPL and mammalian APP selectively interact with heterotrimeric Go (but not other G $\alpha$ proteins) under physiological conditions, consistent with an evolutionarily conserved role for APPGo $\alpha$ signaling in the developing and mature nervous system.

\section{APPL directly binds Go $\alpha$ both in vitro and in vivo}

The model that APPL functions as a Go $\alpha$-associated receptor requires direct contact between the two proteins at the plasma membrane. To address this issue, we used BiFC, a modified "split-GFP" approach whereby complementary fragments of Venus Fluorescent Protein $(\mathrm{Vn})$ are fused to proteins of interest, but they remain nonfluorescent unless brought together by direct interactions between the tagged proteins (Kerppola, 2008; Robida and Kerppola, 2009). For these assays, we fused the $\mathrm{N}$-terminal portion of Venus Fluorescent Protein (Vn1) to the cytoplasmic domain of Manduca APPL (APPL-Vn1) and the complementary C-terminal portion (Vn2) to Go $\alpha$ (Vn2Go $\alpha$ ). As an initial test of these constructs, we transfected them either singly or in combination into COS7 cells, which do not express detectable levels of mammalian Go $\alpha$ or APP (J.M. Ramaker, T.L. Swanson, and P.F. Copenhaver, unpublished observations). After $18-24 \mathrm{~h}$, we then fixed and immunostained the cells with antibodies specific for APPL and Go $\alpha$ to monitor their expression levels (using Alexa Fluor 568- and Alexa Fluor 647coupled secondary antibodies), independent of BiFC-induced fluorescence (visualized in the green channel). As shown in Figure 4, COS7 cells expressing either APPL-Vn1 (Fig. 4A) or Vn2Go $\alpha$ alone (Fig. 4B) showed strong immunoreactivity for the individual fusion constructs but produced no detectable BiFC signal (Fig. $4 A_{3}, B_{3}$ ). In contrast, cells that coexpressed both APPL-Vn1 and Vn2-Goo exhibited robust BiFC signals throughout their somata and growing processes (Fig. $4 C_{3}$ ). These results demonstrate that APPL can directly bind Go $\alpha$ in exogenous cells.

Based on our evidence that the Go-binding domain of APPL is necessary for its association with APPL in vivo (Fig. $3 G$ ), we also tested whether this domain was necessary for direct APPL-Go $\alpha$ interactions in our BiFC assays by cotransfecting COS7 cells with Vn2-Go $\alpha$ and APPL $\Delta$ Go-Vn1 (a form of Manduca APPL lacking the Go-binding domain, amino acids 762-791; Fig. 2B, dotted line). In contrast to the membrane-associated BiFC signals seen in cells that expressed full-length APPL-Vn1 plus Vn2-Go $\alpha$ (Fig. $4 C_{3}$, arrowheads), cells that coexpressed APPL $\Delta$ Go-Vn1 plus Vn2-Go $\alpha$ exhibited only minimal BiFC signals that were confined to the Golgi/endoplasmic reticulum (ER) regions (Fig. $4 D_{3}$ ), despite the presence of both Vn-tagged constructs in more peripheral regions of the cells (Figs. $4 D_{1}, D_{2}$, arrowheads). To directly compare BiFC fluorescence in multiple cells transfected with APPL or APPL $\Delta$ Go, we identified cells with relatively low levels of the Venus-tagged proteins (to avoid saturation in the $\mathrm{BiFC}$ channel) and analyzed the BiFC signal as a ratio to the levels of each construct. Quantification of the relative fluorescent intensities in each channel verified that coexpression of Vn2-Go $\alpha$ with full-length APPL-Vn1 produced significantly stronger BiFC signals than coexpression with APPL $\Delta$ Go-Vn1 (Table 1). These

and with anti-APPL (to detect APPL-Vn1). E, Cotransfection of APPL-Vn1 plus Vn2-Go $\alpha$ produced robust BiFC signals $\left(\boldsymbol{C}_{3}\right)$, indicating direct APPL-Go $\alpha$ binding (arrowheads). $\boldsymbol{F}$, Cotransfection of APPLVn1 with Vn2-Gi $\alpha$ produced only minimal BiFC signals that were primarily localized within the ER/ Golgi regions $\left(\boldsymbol{F}_{3}\right)$. BiFC signals were not apparent in the plasma membrane or growing processes of the cells, despite the presence of both Vn-tagged constructs in these regions $\left(\boldsymbol{F}_{1}, \boldsymbol{F}_{2}\right)$. G, Coexpression of APPL-Vn1 and $V n 2-G s \alpha$ did not result in any detectable BiFC signals $\left(\boldsymbol{G}_{3}\right)$, although both proteins were expressed throughout the cells $\left(\boldsymbol{G}_{1}, \boldsymbol{G}_{2}\right)$. Scale bars: $10 \mu \mathrm{m}$. 
Table 1. Coexpression of APPL plus Go $\alpha$ in COS7 cells produces significantly greater BiFC signals than APPL $\Delta$ Go plus Go $\alpha$

\begin{tabular}{lllc}
\hline Expressed proteins & APPL levels & Go $\alpha$ levels & BiFC levels \\
\hline APPL + Go $\alpha$ & $107 \pm 9$ (ns) & $72 \pm 5$ (ns) & $116 \pm 13^{* * *}$ \\
APPL $\Delta G_{0}+G_{0} \alpha$ & $119 \pm 10$ & $92 \pm 10$ & $9 \pm 2$
\end{tabular}

Quantification of expression levels for APPL, APPL $\Delta G 0, G 0 \alpha$, and BiFC signals in transfected COS7 cells (expressed in relative units per unit area). Fluorescence intensities were calculated from identical regions of the cell membrane and associated filopodia for each channel (as shown in Fig. 4). APPL-Go $\alpha$ interactions produced significantly stronger BiFC signals than APPL $\Delta G_{0}-G_{0} \alpha$ interactions when expressed at similar levels. Each data set shows mean \pm $\mathrm{SEM} ; N=20$ for each sample; ns, no significant difference; ${ }^{* * *} p<0.001$, Student's two-tailed $t$ test.

results show that the Go-binding domain previously identified in human $\mathrm{APP}_{695}$ is also required for direct interactions between APPL and Go $\alpha$.

To test whether APPL selectively interacts with Go $\alpha$ but not other related $\mathrm{G}$ proteins, we also cotransfected COS7 cells with APPL-Vn1 and Vn2-tagged constructs of Gi $\alpha$ or Gs $\alpha$. For these assays, we fixed the transfected cells after $48 \mathrm{~h}$ in culture, and then immunostained them with anti-APPL and an anti-GFP antibody that only recognizes the $\mathrm{Vn} 2$ domain; this approach allowed us to confirm that all of the Vn2-tagged $\mathrm{G} \alpha$ constructs were expressed at comparable levels. As in the previous experiment, cotransfection of APPL-Vn1 with Vn2-Go $\alpha$ produced strong BiFC signals throughout the cells and their growing processes (Fig. $4 E_{3}$, arrowheads). In contrast, cotransfection of APPL-Vn1 with Vn2-Gi $\alpha$ produced only faint BiFC signals that were predominantly restricted to Golgi/ER regions (Fig. $4 F_{3}$, arrowheads), despite the presence of both proteins at the plasma membrane and in growing processes (Fig. $4 F_{1}-F_{3}$ ). Similarly, cells that coexpressed APPL-Vn1 with Vn2-Gs $\alpha$ exhibited no detectable BiFC signals (Fig. $4 G_{3}$ ). These results indicate that APPL directly binds Go $\alpha$ but not other related $\mathrm{G}$ proteins in cell culture, consistent with the model that APPL selectively interacts with Go $\alpha$ at the plasma membrane.

To complement our analysis of APPL-Go $\alpha$ interactions in vitro, we also used the UAS-GAL4 system to express APPL-Vn1 and Vn2-Go $\alpha$ within the fly nervous system. For these experiments, we induced expression of UAS-APPL-Vn1 and UAS-Vn2Go $\alpha$ using the eye-specific GMR-GAL4 promoter construct. Developing eye discs were then collected at progressive stages of development, fixed, and immunostained with a polyclonal antiGFP antibody that recognized both $\mathrm{Vn} 1$ and $\mathrm{Vn} 2$ (visualized with Alexa Fluor 568-conjugated secondary antibodies), allowing us to monitor their expression levels in addition to the BiFC signals that they produced (Fig. $5 A-C$ ). When we expressed either APPL-Vn1 (Fig. $5 A_{1}$ ) or Vn2-Go $\alpha$ alone (Fig. $5 B_{1}$ ), we could readily detect the constructs in developing adult photoreceptors within the eye discs, but (as expected) no BiFC signals were produced (Fig. $5 A_{2}, B_{2}$ ). In contrast, coexpression of APPL-Vn1 with $\mathrm{Vn} 2-\mathrm{Go} \alpha$ resulted in robust BiFC signals within the photoreceptor membranes and their axonal projections extending into the developing adult brain (Fig. $5 C_{2}$ ). These results demonstrate that APPL and Go $\alpha$ directly bind when coexpressed in vivo, similar to our results in COS7 cells.

To explore whether APPL-Go $\alpha$ interactions could be visualized in synaptic regions within the brain, we also examined younger third instar larvae, when GMR-induced expression can also be detected in 12 bilaterally paired larval photoreceptors that project into the brain (Steller et al., 1987; Hartenstein, 1988). As shown in Figure $5 D$, BiFC signals produced by coexpression of APPL-Vn1 with Vn2-Go $\alpha$ could be readily detected in larval photoreceptor axons extending through the developing eye disc via Bolwig's nerve and into the larval optic neuropil (Fig. $5 D_{2}$ ), where they make synaptic contacts with several classes of interneurons (Tix et al., 1989; Sprecher et al., 2011). In contrast, when we coexpressed UAS-Vn2-Go $\alpha$ with UAS-APPL $\Delta$ GoVn1 (lacking the Go binding domain of APPL) at similar levels, no detectable BiFC signals were produced (Fig. $5 E$ ); again demonstrating that this domain is required for APPL-Go $\alpha$ interactions in vivo. At slightly later stages (white pupae), BiFC signals also became apparent within the developing synaptic terminals of adult photoreceptors coexpressing APPL-Vn1 and Vn2-Go $\alpha$ in the lamina cortex (Fig. $5 F$ ). These results confirm our immunohistochemical evidence that endogenously expressed Go $\alpha$ colocalizes with APP family proteins in developing neurons, providing additional support for the model that APP-Go $\alpha$ signaling may play a functional role in regulating key aspects of neuronal motility.

\section{APPL-Go $\alpha$ interactions are regulated by Go $\alpha$ activity}

A prediction from the model that APPL functions as an authentic G protein-coupled receptor (GPCR) is that APPL should preferentially bind inactive Go $\alpha$ as part of a heterotrimeric complex, whereas activation of Go $\alpha$ should promote its dissociation from APPL (Fig. 6A). To address this issue, we use our coimmunoprecipitation assays to determine whether stimulating $\mathrm{G}$ protein activity affected basal APPL-Go $\alpha$ interactions. As an initial test, we prepared lysates from Manduca GV1 cells (which endogenously express both proteins) and verified that APPL and Go $\alpha$ could be readily coimmunoprecipitated with anti-cAPPL antibodies (Fig. $6 B$, lane 1 ; histogram values in Fig. $6 B$ were calculated by normalizing coimmunoprecipitated Go $\alpha$ levels relative to untreated controls). In contrast, treating replicate samples with GTP $\gamma \mathrm{S}$, a nonhydrolyzable GTP analog that activates all G proteins (Stryer and Bourne, 1986), reduced APPL-Go $\alpha$ interactions in a concentration-dependent manner (Fig. 6B, lanes 2-4). Treating lysates with GDP $\beta S$, which inhibits $G$ protein activation, slightly increased Go $\alpha$-APPL interactions (Fig. 6B, lane 6). These results indicate that APPL preferentially binds inactive but not active Go $\alpha$, consistent with the hypothesis that APPL may function as a Go $\alpha$-associated receptor rather than a downstream target of Go $\alpha$ signaling.

A potential caveat to the foregoing experiments is that GDP/ GTP analogs can modulate the activity of both heterotrimeric and monomeric G proteins (Stryer and Bourne, 1986) and might affect APPL-Go $\alpha$ interactions both directly and indirectly. We therefore performed a similar analysis with reagents that selectively target Go $\alpha$, using lysates prepared from Manduca embryos at 60-70 hpf (during the active period of EP cell migration and outgrowth). Lysates were immunoprecipitated with anti-cAPPL, and the immunoblots labeled with both anti-Go $\alpha$ (Fig. 6C, upper gel) and anti-nAPPL (Fig. 6C, lower gel); the doublet labeled by the double arrows in Figure $6 C$ indicates the immature and mature forms of full-length APPL, respectively (Swanson et al., 2005). For these experiments, relative levels of coimmunoprecipitated Go $\alpha$ were normalized to APPL levels in each sample, and then quantified as a ratio compared with untreated controls. Because insect APPL is exclusively expressed by neurons (Luo et al., 1990; Swanson et al., 2005), this approach provided a means of testing how Go $\alpha$ activity affects its association with endogenous APPL in the developing nervous system. As shown in Figure $6, C$ (lanes 1-2), treatment with GTP $\gamma \mathrm{S}$ dramatically reduced the amount of Go $\alpha$ that could be coimmunoprecipitated with APPL, compared with untreated controls. Likewise, treatment with the Go $\alpha$ activator Mas 7 (a potent analog of Mastoparan) caused a substantial reduction in APPL-Go $\alpha$ interactions at all concentra- 

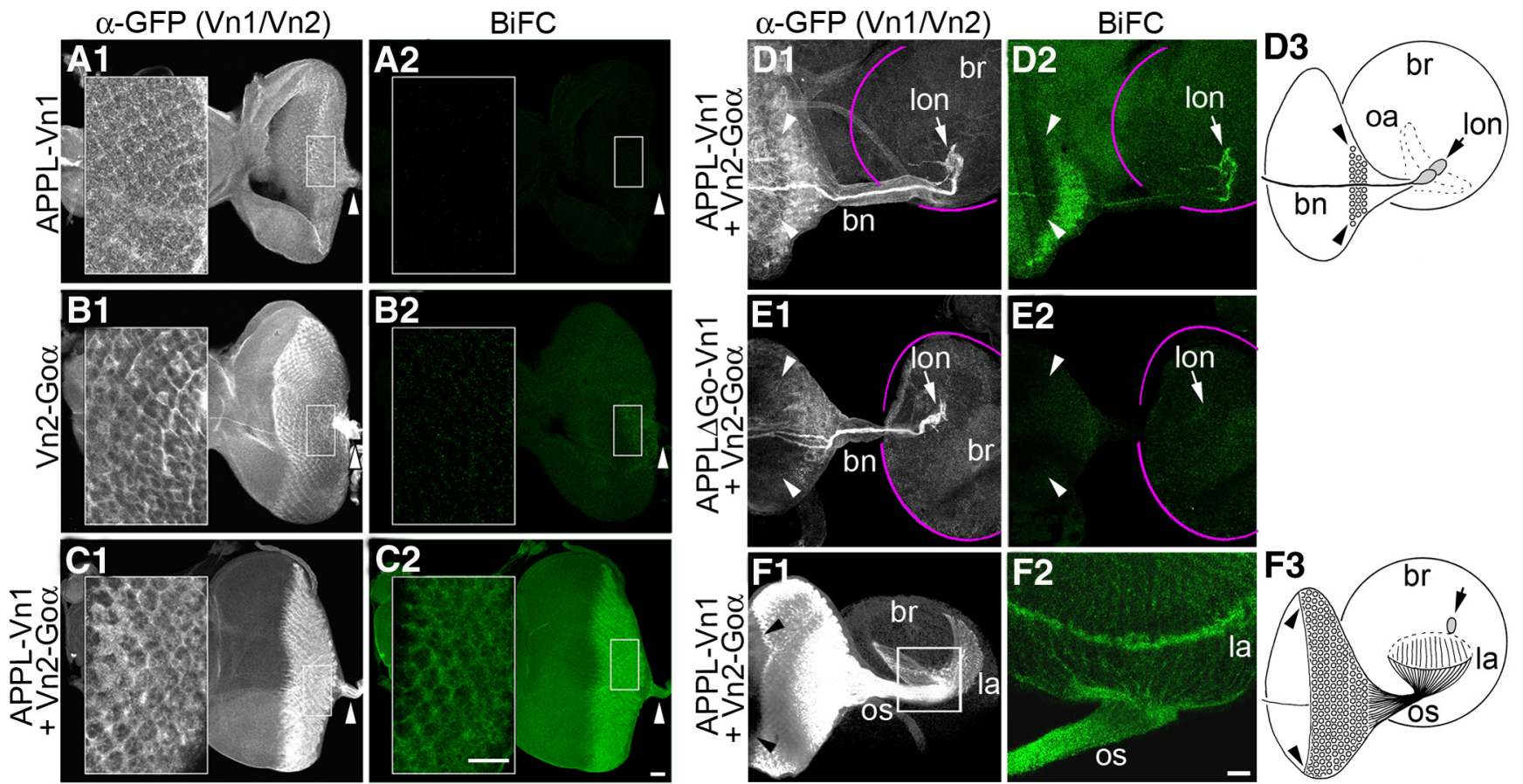

Figure 5. APPL and Go $\alpha$ directly interact in Drosophila photoreceptors and developing synapses. Isolated eye discs from third instar larvae expressing UAS-APPL-Vn1, UAS-Vn2-Go $\alpha$, or both constructs (controlled by GMR-GAL4). Discs were fixed and immunostained with $\alpha$-GFP (Aves \#GFP1020) to label both Vn1 and Vn2 epitopes (visualized with Alexa Fluor 568 secondary antibodies); BiFC signals produced by APPL-Go $\alpha$ interactions were imaged in the green channel. $\boldsymbol{A}_{\boldsymbol{1}}, \boldsymbol{B}_{1}$, Eye discs expressing either APPL-Vn1 or Vn2-Go $\alpha$ alone did not exhibit detectable BiFC signals $\left(\boldsymbol{A}_{2}, \boldsymbol{B}_{2}\right)$. $\boldsymbol{C}_{1}$, Coexpression of APPL-Vn1 and Vn2-Go $\alpha$ resulted in robust BiFC signals throughout the fly photoreceptors $\left(\boldsymbol{C}_{2}\right)$ and their axonal projections extending into the optic stalk (arrowheads). Small white boxes in the low-magnification images indicate highlighted regions shown in the insets of each panel. $\boldsymbol{D}, \boldsymbol{E}$, Isolated eye disc-brain complexes from mid-third instar Drosophila larvae that expressed Vn2-Go $\alpha$ plus either wild-type APPL-Vn1 or APPL $\Delta G_{0}-V_{n} 1$. Magenta outlines demarcate the proximal brain lobe (br) in each preparation. $\boldsymbol{D}_{1}, \boldsymbol{E}_{1}$, Eye disc-brain complexes from mid-third instar larvae coexpressing Vn2-Go $\alpha$ plus mutated or wild-type forms of APPL-Vn1. Immunostaining for anti-GFP showed that the Venus-tagged constructs were expressed in the developing adult photoreceptors (adjacent to the morphogenetic furrow; arrowheads) and throughout Bolwig's nerve (bn), which carries the axons of 12 larval photoreceptors through the eye disc into the larval optic neuropil of the brain (lon; arrows). Larval photoreceptors are out of the field of view. $\boldsymbol{D}_{2}$, The combined expression of APPL-Vn1 and Vn2-Go $\alpha$ produced robust BiFC signals in regions where both proteins were coexpressed (indicative of direct APPL-Go $\alpha$ interactions), including the synaptic projections of the larval photoreceptors in the lon. $\boldsymbol{E}_{2}$, Coexpression of APPL $\Delta$ Go-Vn1 plus Vn2-Go $\alpha$ produced no detectable BiFC signals, despite comparable expression levels for both APPL constructs in $\boldsymbol{D}$ and $\boldsymbol{E}$ (data not shown). $\boldsymbol{D}_{3}$, Schematic representation of the late third instar larval eye disc- brain complex (equivalent to dissected preparations in $\boldsymbol{D}$ and $\boldsymbol{E}$ ), illustrating the orientation of bn and the lon. Arrowheads indicate the morphogenetic furrow; dotted outline in the br indicates the adult optic anlage (oa), forming adjacent to the lon. $\boldsymbol{F}$, Eye disc-brain complex from a white pupa expressing APPL-Vn1 plus Vn2-Go $\alpha$. $\boldsymbol{F}_{1}$, Immunostaining with anti-GFP revealed the expression of the Venus-tagged constructs in developing adult photoreceptors, their projecting axons in the optic stalk (os), and their differentiating synaptic terminals within the lamina cortex (la) of the brain. $\boldsymbol{F}_{2}$, Magnified image of the boxed region in $\boldsymbol{F}_{1}$ (compressed image of 16 optical sections) to highlight the presence of BiFC signals in the photoreceptor axons within the os and their synaptic terminals in the la. $\boldsymbol{F}_{3}$, Schematic representation of the eye disc- brain complex at the white pupal stage (equivalent to preparation in $\boldsymbol{F}_{1}$ ), illustrating the orientation of the os and la regions; small oblong circle (gray) indicates the position of the residual lon (not visible in $\boldsymbol{F}_{1}$ and $\boldsymbol{F}_{\mathbf{2}}$ ). Scale bars: (in $\boldsymbol{A}-\boldsymbol{C}$ ) $25 \mu \mathrm{m}$; (in $\boldsymbol{A}-\boldsymbol{C}$ inset boxes) $15 \mu \mathrm{m} ; \boldsymbol{D}-\boldsymbol{F}_{\mathbf{1}}, 30 \mu \mathrm{m}$; (in $\boldsymbol{F}_{\mathbf{2}}$ ) $10 \mu \mathrm{m}$.

tions (Fig. 6C, lanes 3-4; and data not shown). Although Mas 7 will also activate Gi $\alpha$ (Higashijima et al., 1990), our evidence that APP family proteins associate with Go $\alpha$ but not other G proteins (Fig. 3) suggests that the effects of Mas 7 were specific to Go $\alpha$ in this assay. In contrast, treatment with PTX caused a dramatic increase in the amount of Go $\alpha$ that coimmunoprecipitated with APPL (Fig. 6C, lanes 5-6). Since PTX inhibits insect Go $\alpha$ but not Gi $\alpha$ (which lacks the C-terminal cysteine targeted for ADP-ribosylation; Thambi et al., 1989), these results indicate that the inactivation of Go $\alpha$ specifically inhibits its dissociation from APPL. None of these treatments significantly altered APPL levels (Fig. $6 \mathrm{C}$, double arrowheads), indicating that the observed changes in APPL-Go $\alpha$ interactions were not caused by accelerated cleavage or degradation of the holoprotein. Figure $6 D$ summarizes the combined results of multiple experiments using these methods, showing that both GTP $\gamma S$ and Mas 7 caused significant decreases in coimmunoprecipitated Go $\alpha$. In contrast, treatment with PTX caused a concentration-dependent increase in APPL-Go $\alpha$ interactions, ranging from a slight enhancement at $1 \mu \mathrm{g} / \mathrm{ml}$ to highly significant increases at $2-4 \mu \mathrm{g} / \mathrm{ml}$ (Fig. $6 D$; and data not shown). In some preparations, GDP $\beta$ S also caused an increase in the level of coimmunoprecipitated Go $\alpha$, although this response was more variable and did not reach statistical significance at the concentrations used for these assays. In combination, these experiments support the model that stimulation of APPL signaling within neurons will induce the activation and release of Go $\alpha$, similar to conventional GPCRs. They also suggest that under normal conditions, a low level of APPL activation coincides with EP cell migration and outgrowth, consistent with a role for APP family proteins in regulating motile responses to endogenous guidance cues.

\section{APPL and Go $\alpha$ signaling regulates common aspects of neuronal migration}

To test whether APPL-Go $\alpha$ signaling regulates specific aspects of neuronal motility in vivo, we used our well characterized embryo culture assay for neuronal migration in Manduca (Horgan et al., 1995; Coate et al., 2008). Developmentally synchronous embryos were opened in culture to expose the ENS before the onset of migration (at 52-53 hpf; Fig. 7A), and the EP cells were directly challenged with experimental reagents targeting either Go $\alpha$ or APPL. The embryos were allowed to develop in culture for an additional $24 \mathrm{~h}$, and then fixed and immunostained with anti-Fas II to quantify the full extent of EP cell migration and axon out- 


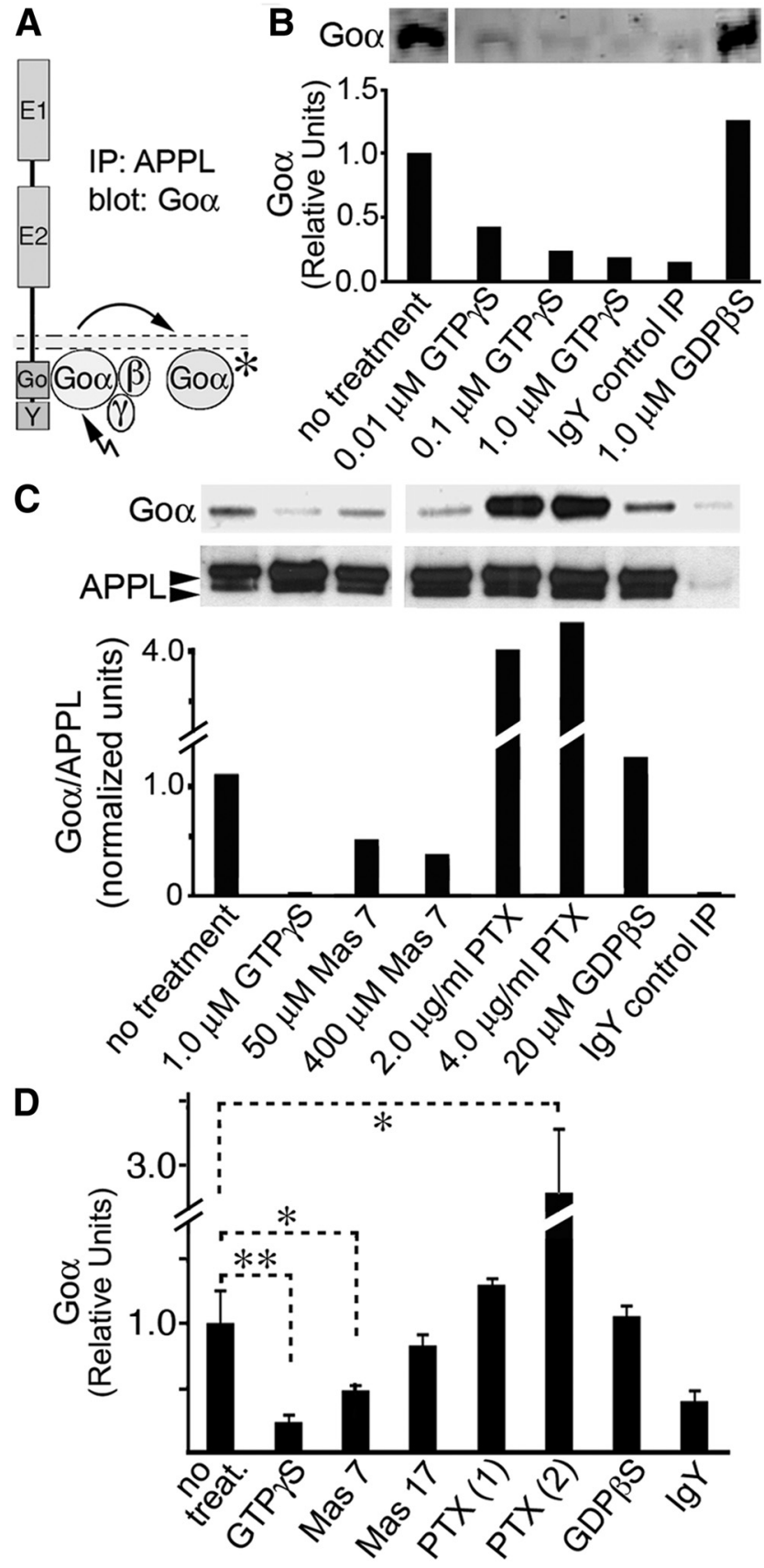

Figure 6. APPL-Go $\alpha$ interactions are regulated by $G_{0} \alpha$ activity. $A$, Schematic of the model that inactive $\mathrm{Go} \alpha$ binds APPL as part of a heterotrimeric complex with $\mathrm{G} \beta \gamma$. Activation of $\mathrm{G}_{0} \alpha$ (normally due to the exchange of bound GDP for GTP) promotes its dissociation from APPL, whereas inhibiting $\mathrm{Go} \alpha$ prevents this dissociation, resulting in an increase in basal APPL-Go $\alpha$ interactions. $\boldsymbol{B}$, Replicate cultures of Manduca GV1 cells (which endogenously express APPL and $\mathrm{Go} \alpha$ ) were treated as indicated, then lysed, immunoprecipitated with $\alpha$-APPL, and immunoblotted with anti-Go $\alpha$. Relative levels of coimmunoprecipitated Go $\alpha$ were normalized to "no treatment" control run in parallel (lane 1). Stimulating G protein activity with GTP $\gamma S$ (a nonhydrolyzable activator of $G$ proteins) led to a concentration-dependent reduction in the amount of Go $\alpha$ that coimmunoprecipitated with APPL (lanes $2-4$ ). IgY = matched negative control immunoprecipitation (lane 5). Treatment with GDP $\beta S$ (a nonhydrolyzable G protein inhibitor) caused a modest increase in APPL-Go $\alpha$ interactions (lane 6). C, Lysates from staged groups of embryos (60-65 hpf) were treated as indicated, immunoprecipitated with $\alpha$-APPL, and immunoblotted with anti-Go $\alpha$. Gel shows a representative Western blot of coimmunoprecipitated Go $\alpha$ (upper blot) and APPL (lower blot; labeled with anti-nAPPL). Double arrow indicates the immature (smaller) and mature (larger) forms of full-length APPL. Go $\alpha$ levels were calculated as a ratio of immunoprecipitated full-length APPL in the same sample, and ratios were normalized to untreated controls (lane 1). Treatment with $1.0 \mu \mathrm{M}$ GTP $\gamma 5$ decreased growth. As shown in Figure $7 B$, embryos treated with control medium during this period exhibited a normal pattern of migration and outgrowth that was predominantly restricted to the midgut muscle bands (Figure $7 B, \mathrm{~b}$ ), with relatively few neurons and processes extending onto the interband regions (Figure $7 B$, ib). Treating the EP cells with $\mathrm{AlF}_{4-}$ to selectively stimulate heterotrimeric G protein activity (Sternweis and Gilman, 1982) curtailed their subsequent migration and outgrowth (Fig. 7C,E), similar to the effects of both GTP $\gamma \mathrm{S}$ (which stimulates all G proteins) and mastoparan (specific for Go $\alpha$ and Gi $\alpha$; Horgan et al., 1994, 1995). In contrast, inhibiting Go $\alpha$ with PTX resulted in a distinctive pattern of ectopic migration and outgrowth by the EP cells onto the interband regions (Fig. $7 D, F, G$ ), as well as a moderate increase in their average distance traveled along the normal band pathways (Fig. 7E). To confirm the specificity of this effect, we also treated premigratory neurons with the A-Protomer of PTX (which lacks the lectin-like activity of the B-oligomer; Mangmool and Kurose, 2011), using $\alpha$ toxin to enhance cell penetration (as previously described; Horgan et al., 1995). As shown in Figure 7, $F$ and $G$, this treatment induced a more dramatic increase in the number of ectopic neurons and neurites that extended into the interband regions, as well as a moderate but significant increase in migration and growth along the band pathways (Fig. 7E). Treatment with $\alpha$ toxin alone caused no significant effects (data not shown). These results are consistent with our previous evidence that $\operatorname{Go} \alpha$ activity normally restricts the extent of EP cell migration in a $\mathrm{Ca}^{2+}$-dependent manner (Horgan and Copenhaver, 1998).

Based on reports that APP family proteins can regulate neuronal migration in other systems (Herms et al., 2004; YoungPearse et al., 2007) and our evidence that APPL endogenously interacts with Go $\alpha$ in the developing ENS, we tested whether altering APPL expression in the EP cells induced similar defects in their migratory behavior. We first evaluated a panel of morpholinos targeting the coding domain of Manduca APPL mRNA for their effectiveness in knocking down APPL expression in GV1 cells. As shown in Figure 8A, one of these morpholinos (MOAPPL2) caused significant reductions in APPL levels that were both concentration-dependent and specific, almost completely eliminating APPL protein levels (Fig. 8B) without affecting Go $\alpha$ or tubulin expression (used as off-target controls; Fig. 8A,B). Staged embryos were then opened in culture at $48 \mathrm{hpf}$ ( $7 \mathrm{~h}$ before migration onset) and treated with either MO-APPL2 or control morpholinos for $24 \mathrm{~h}$, using Endo-Porter to facilitate their transport into developing neurons (Coate et al., 2008). Compared

APPL-Go $\alpha$ interactions (lane 2). Treatment with Mas 7 (to activate Gi $\alpha / G_{0} \alpha$ ) decreased APPL-Go $\alpha$ interactions in a concentration-dependent manner (lanes 3-4). In contrast, inhibiting Go $\alpha$ with PTX enhanced APPL-Go $\alpha$ interactions (lanes 5-6). Treatment with $20 \mu \mathrm{m}$ GDP $\beta S$ caused only a minor increase in coimmunoprecipitated Go $\alpha$ levels (lane 7). $\lg \gamma=$ negative control immunoprecipitation (lane 8). $\boldsymbol{D}$, Combined analysis of multiple experiments in which Manduca embryonic lysates were treated with G-protein-specific reagents, then immunoprecipitated with anti-CAPPL and immunoblotted with anti-Go $\alpha$. Each manipulation was repeated in at least three independent experiments and normalized to their respective untreated controls in the same assay. Treatment with both GTP $\gamma$ S and Mas 7 significantly reduced APPL-Go $\alpha$ interactions. Mas 17, an inactive mastoparan analog, had no significant effect, compared with controls. PTX induced a concentration-dependent increase in APPL-Go $\alpha$ interactions. Although treatment with GDP $\beta S$ caused a slight increase in APPL-Go $\alpha$ interactions in some experiments, overall this effect was not significant at the concentrations tested. IgY represents the species-matched negative control immunoprecipitations performed in each assay. Pairwise statistical analyses were performed between the control and each experimental group using Student's two-tailed $t$ tests, ${ }^{*} p<0.05 ;{ }^{* *} p<0.01$. Error bars indicate SEM. 


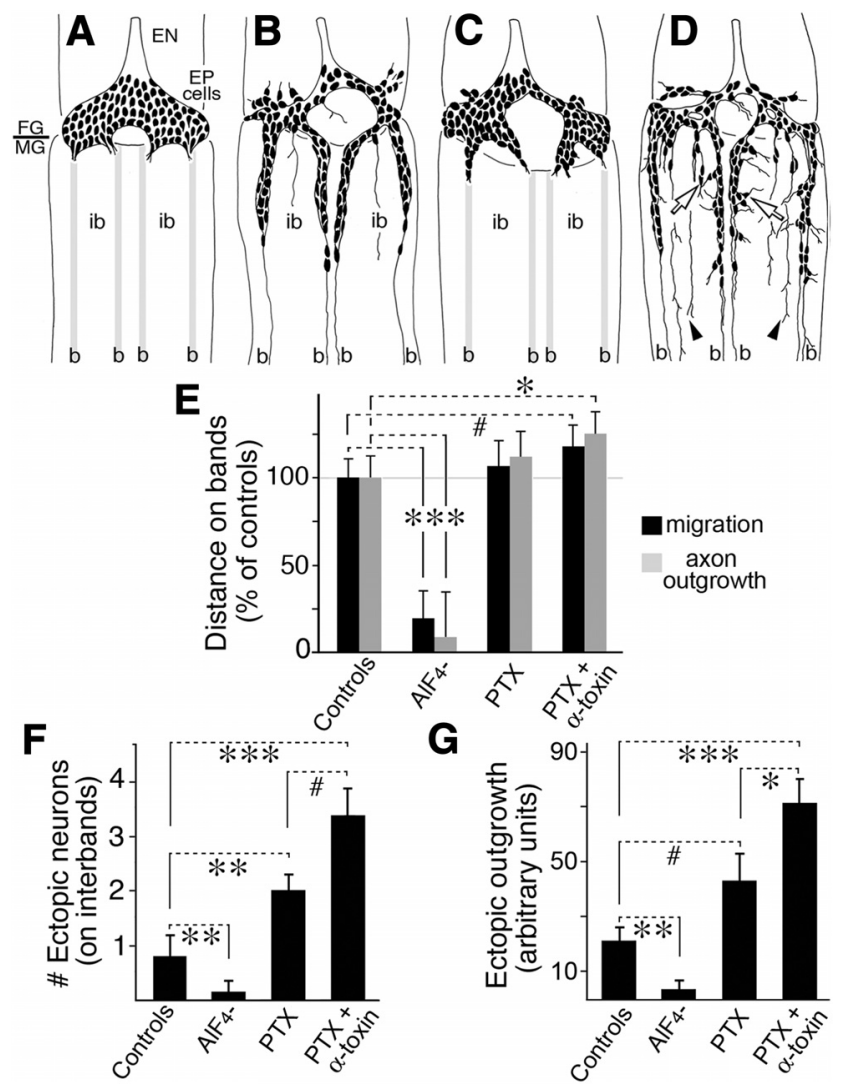

Figure 7. Inhibiting Go $\alpha$ activity in the EP cells induces ectopic migration and outgrowth. $\boldsymbol{A}-\boldsymbol{D}$, Representative camera lucida drawings of Manduca embryos in which the EP cells were treated before migration onset with reagents targeting $\mathrm{G}_{0} \alpha$, grown in culture for another $24 \mathrm{~h}$, then fixed and immunostained with anti-Fas II to reveal the full extent of migration and outgrowth in the developing ENS. $\boldsymbol{A}$, Control embryo immunostained at the onset of an experiment (52 hpf) to show the initial positions of the premigratory EP cells adjacent to the FG/MG boundary. By this stage, subsets of neurons had begun to extend exploratory filopodia onto their future muscle band pathways (b) but had not commenced their migratory dispersal. $\boldsymbol{B}$, Embryo opened at $52 \mathrm{hpf}$ and treated with control culture medium throughout $24 \mathrm{~h}$ of development showed the normal pattern of migration and outgrowth along the muscle bands, with only a few processes growing onto the interband musculature (ib). C, Treatment with $12.5 \mu \mathrm{m} \mathrm{AlF}_{4-}$ (an activator of heterotrimeric $G$ proteins) caused almost complete inhibition of migration and outgrowth, stalling the neurons at the FG/MG boundary. D, Treatment with $100 \mathrm{ng} / \mathrm{mI} \mathrm{PTX} \mathrm{(a}$ specific inhibitor of Go $\alpha$ in insects) induced a distinctive pattern of ectopic migration (open arrows) and outgrowth onto the interband regions (black arrowheads). $\boldsymbol{E}$, Average distances of neuronal migration and axon outgrowth along band pathways for each treatment group (normalized to matched sets of control embryos in each experiment). $\boldsymbol{F}$, Quantification of the average number of neurons per embryo that exhibited ectopic migration into each interband region for each treatment condition. G, Quantification of the average extent of ectopic axon outgrowth in the interband regions of embryos treated with various reagents. In $\boldsymbol{E}-\boldsymbol{G}$, pairwise statistical analyses were performed between each experimental group and their corresponding controls, using Student's two-tailed $t$ tests, ${ }^{*} p<0.05 ;{ }^{*} p<0.02 ;{ }^{* *} p<0.01 ;{ }^{* * *} p<0.001 . N=$ at least 10 per condition. Error bars indicate SEM.

with the infrequent ectopic events seen in embryos treated with control morpholinos (Fig. 8G), knocking down APPL expression in the EP cells resulted in a pattern of excessive migration and outgrowth onto the interband regions (Fig. 8D, G,H), a phenotype strikingly similar to the ectopic growth induced by PTX treatment (Fig. 7D). Because our methods for visualizing the EP cells (with anti-Fas II immunostaining) precluded a simultaneous analysis of APPL expression, it was not possible to directly correlate the extent of ectopic growth by individual neurons and their residual APPL levels. Nevertheless, quantifying these effects for the entire population of EP cells indicated that inhibiting
APPL expression resulted in the same distinctive pattern of ectopic growth and migration caused by inhibiting Go $\alpha$ activity.

Although several candidate proteins have now been shown to interact with APP family proteins in different contexts (Ho and Südhof, 2004; Osterfield et al., 2008; Rice et al., 2012), authentic ligands that regulate their intrinsic signaling activity have yet to be identified. As an alternative strategy, we used our anti-nAPPL antibody (targeting the extracellular domain of APPL) to block endogenous interactions between APPL and its putative binding partners, as a means of testing whether APPL-dependent signaling is required for their normal pattern of migration and outgrowth. Accordingly, staged embryos were opened in culture shortly before the onset of migration (52-23 hpf), and the EP cells were directly treated with medium containing either anti-nAPPL or control IgG. Imaging these preparations after $24 \mathrm{~h}$ revealed the same pattern of ectopic growth and migration caused by PTX treatment and APPL-specific morpholinos (Figs. 8E,G,H), whereas none of these treatments had a significant effect on the extent of migration and axon growth along the band pathways (Fig. $8 F$ ). Thus, inhibition of either APPL or Go $\alpha$ activity produced an identical phenotype within the developing ENS, in which the migratory neurons and their processes traveled inappropriately into regions that were normally inhibitory to neuronal growth.

The dramatic effects caused by perturbing APPL signaling in our embryonic culture assays were particularly striking, compared with the relatively subtle phenotypes induced by the genetic deletion of APPL. In flies lacking APPL, the initial formation of the nervous system was surprisingly normal (Luo et al., 1992), although these animals displayed more subtle defects in axonal targeting and postsynaptic synaptic growth (Ashley et al., 2005; Mora et al., 2013), and they exhibited aberrant responses to both neurodegenerative insults and traumatic brain injury (Leyssen et al., 2005; Wentzell et al., 2012). Flies lacking APPL also exhibited behavioral and learning deficits that could be rescued by re-expression of APPL or human APP (Luo et al., 1992). These results are consistent with the model that APPL-dependent interactions modulate multiple aspects of neuronal motility throughout life. In comparison, genetic deletion of Go $\alpha$ in Drosophila caused more extensive abnormalities in neuronal growth and guidance, including errors in axonal guidance, fasciculation, and target innervation (Frémion et al., 1999), suggesting that additional guidance factors in addition to APPL normally contribute to the homeostatic control of Go $\alpha$ in the nervous system. In this manner, the local control of Go $\alpha$ activity within motile neurons may provide a convergent mechanism for integrating their responses to a range of attractive and repulsive stimuli (He et al., 2006; Bromberg et al., 2008). The dramatic patterns of ectopic growth caused by our acute manipulations of APPL in the ENS may therefore reflect a lack of compensatory modulation of Go $\alpha$ signaling over the relatively short time course of our embryonic culture assays.

In combination with previous evidence that local activation of Go $\alpha$ in the EP cells induces $\mathrm{Ca}^{2+}$-dependent filopodial retraction (Horgan and Copenhaver, 1998), we propose that APPL (and its vertebrate orthologs) can function as unconventional Go $\alpha$ associated receptors that regulate the motile behavior of developing neurons (Fig. 9). By this model, transmembrane APPL normally trafficks to the leading processes of developing neurons, where it assembles into a signaling complex with Go $\alpha$. Interactions between APPL on exploratory filopodia and unidentified ligands on adjacent cells induce the local activation and release of $\mathrm{Go} \alpha$, which in turn promotes $\mathrm{Ca}^{2}$-dependent filopodial retrac- 
A
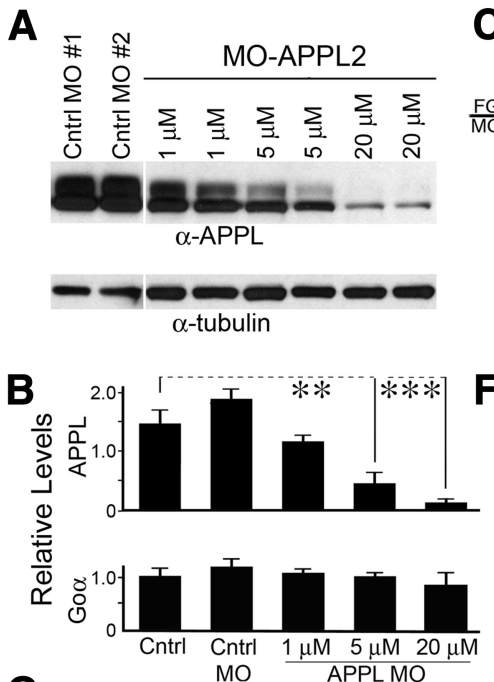

G

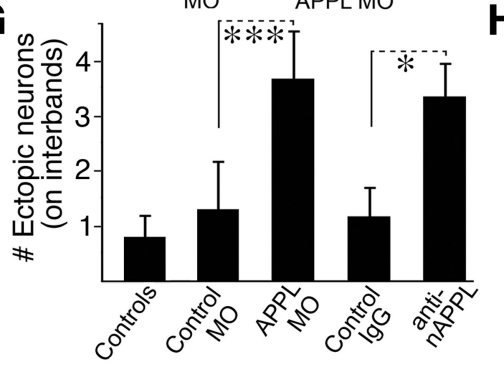

H

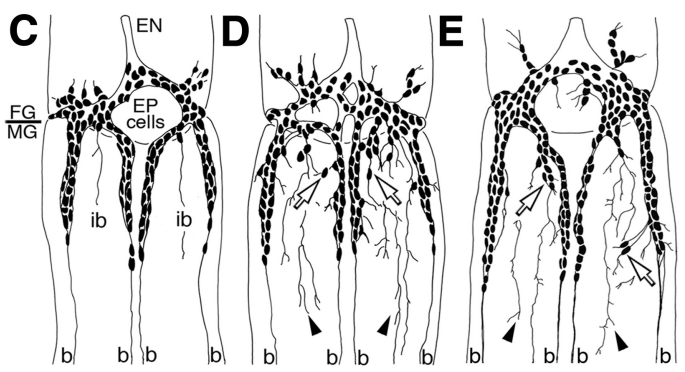

$\mathbf{F}$
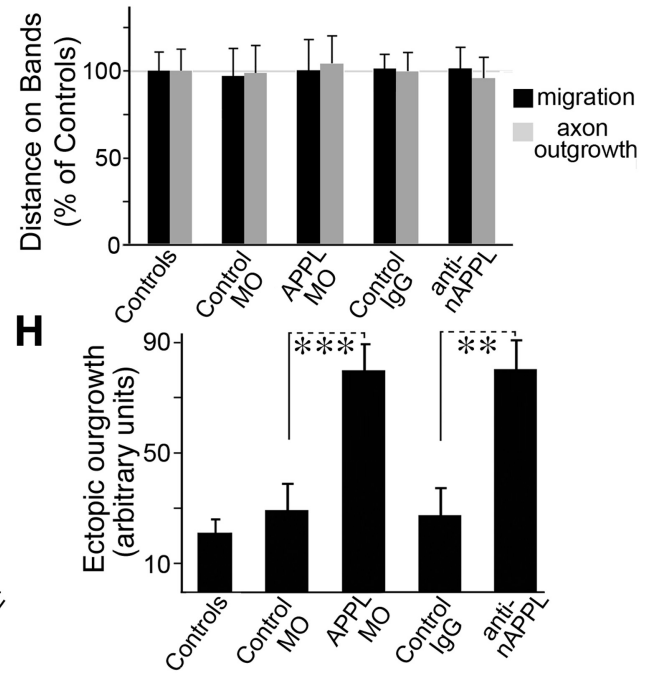

Figure 8. Disrupting APPL signaling in the EP cells induces ectopic migration and outgrowth. $A$, Western blot of Manduca GV1 cells treated with APPL-specific morpholinos (MOs) for $48 \mathrm{~h}$, then lysed and immunoblotted with anti-APPL to demonstrate the selective knock down of APPL expression. Immunoblotting the same gel with anti-tubulin served as a control for nonspecific effects of the M0s. Lanes 1-2: Replicate GV1 cell lysates treated with $20 \mu \mathrm{m}$ standard control MOs (plus $0.6 \%$ Endo-Porter). Lanes 3-8: Replicate lysates treated with $0.6 \%$ Endo-Porter plus increasing concentrations of APPL MOs. B, Quantification of replicate experiments demonstrating the effectiveness of the APPL MOs at different concentrations (normalized to tubulin levels); treatment with 5 and $20 \mu \mathrm{m}$ APPL significantly inhibited APPL protein levels. Quantification of $G_{0} \alpha$ levels in the same samples (also normalized to tubulin) showed that $G 0 \alpha$ was unaffected by the MO treatments. $\mathbf{C}-\boldsymbol{H}$, Inhibiting APPL signaling in the EP cells phenocopies the effect of inhibiting Go $\alpha$ activity on ectopic migration and outgrowth. $C-E$, Camera lucida drawings of Manduca embryos in which the EP cells were treated before migration onset with reagents targeting APPL signaling, allowed to develop in culture for another $24-48 \mathrm{~h}$, then fixed and immunostained with anti-Fas II to reveal the full extent of migration and outgrowth. C, Control embryo treated with culture medium exhibited a normal pattern of migration and outgrowth (same preparation shown in Fig. 7B). D, Treatment with APPL-specific MOs ( $50 \mu \mathrm{g} / \mathrm{ml}$ ) induced the same overall pattern of ectopic migration and outgrowth caused by inhibiting Go $\alpha$ activity. $\boldsymbol{E}$, Treatment with anti-nAPPL $(1 \mu \mathrm{g} / \mathrm{ml})$ also induced a similar phenotype. Open arrows in $\boldsymbol{D}$ and $\boldsymbol{E}$ indicate ectopic neurons in the interband regions; black arrowheads indicate ectopic processes. $\boldsymbol{F}$, Average distances of neuronal migration and axon outgrowth along the band pathways for each treatment group (normalized to matched sets of control embryos in each experiment). $\mathbf{G}$, Quantification of the average number of neurons that exhibited ectopic migration onto the interband regions for each treatment condition. $\boldsymbol{H}$, Quantification of the average extent of ectopic axon outgrowth per interband region for each treatment condition. ${ }^{*} p<0.05 ;{ }^{\#} p<0.02 ;{ }^{* *} p<0.01 ;{ }^{* * *} p<0.001$; Student's two-tailed $t$ tests. $N=$ at least 10 per condition. Error bars indicate SEM.

tion. Global stimulation of this pathway should therefore induce a collapse/stall response in migration (as caused by activators of Go $\alpha$ ), whereas inhibition of either APPL or Go $\alpha$ should permit ectopic, inappropriate migration and outgrowth (as illustrated by the foregoing manipulations). In this manner, APPL and its vertebrate orthologs might contribute to the dynamic positioning of neurons and their processes within the developing nervous system and in regions of synaptic plasticity in the adult brain.

\section{Discussion}

APP family proteins as unconventional

Go $\alpha$-coupled receptors

Evidence that APP can function as a Grotein-associated receptor originated from studies by Nishimoto et al. (Nishimoto et al., 1993; Okamoto et al., 1995), who used reconstituted phospho- lipid vesicles to show that clustered APP can activate $\mathrm{Go} \alpha$ via a 20 aa sequence within its cytoplasmic domain. However, the physiological role of APP as an authentic regulator of $\mathrm{Go} \alpha$ activity has remained unclear. We have now used several different approaches to show that endogenously expressed APPL (in insects) and APP (in mammals) interact with Go $\alpha$ in the nervous system. Simultaneous immunolabeling with antibodies against both the $\mathrm{N}$ - and C-terminal domains of APP and APPL indicated that the full-length forms of these proteins colocalize with $\mathrm{Go} \alpha$ in regions of active motility, including the leading processes of migrating neurons and the growth cones of elongating neurites (Figs. 1, 2). Likewise, our coimmunoprecipitation analysis showed that both full-length APPL and APP interact with endogenously expressed Go $\alpha$, in contrast to other related $\mathrm{G} \alpha$-subunits (including Gi $\alpha$ and Gs $\alpha$; Fig. 3). Using genetically modified Drosophila lines, we demonstrated that the conserved Go-binding domain within APPL is required for this interaction (Fig. $3 G$ ), providing new support for the model proposed by Nishimoto et al (1993). A pharmacological analysis of APPL-Go $\alpha$ interactions in lysates from Manduca cells and embryos demonstrated that activation of Go $\alpha$ induced its dissociation from APPL, whereas inhibiting Go $\alpha$ enhanced APPL-Go $\alpha$ interactions (Fig. 6), paralleling the effects of similar manipulations targeting conventional GPCRs (Mangmool and Kurose, 2011).

Last, we adapted BiFC protocols to show that APPL directly interacts with Go $\alpha$ (but not other G $\alpha$-subunits) in transfected COS7 cells (Fig. 4) and within the fly nervous system (Fig. 5). Consistent with our coimmunoprecipitation assays, we found that the production of BiFC signals by APPL-Go $\alpha$ interactions required the conserved Go-binding domain in APPL (Figs. 4, 5). These results provide the first demonstration that APPL and Go $\alpha$ can directly bind in vivo, and they support the model that APP family proteins represent a distinct class of unconventional (single-transmembrane) Go $\alpha$ coupled receptors (Patel, 2004).

\section{APP family proteins and the control of neuronal migration} Although the normal functions of APP and its orthologs remain controversial, considerable evidence indicates that they can regulate multiple aspects of neuronal motility. Developmentally expressed APP (in mammals) and APPL (in insects) are upregulated in regions of active growth and migration (Luo et al., 1990; Clarris et al., 1995; Torroja et al., 1999a; Sabo et al., 2003; Swanson et al., 2005; Young-Pearse et al., 2007), while both the transmembrane holoproteins and their cleaved ectodomain fragments are capable of modulating cell adhesion responses, neurite 


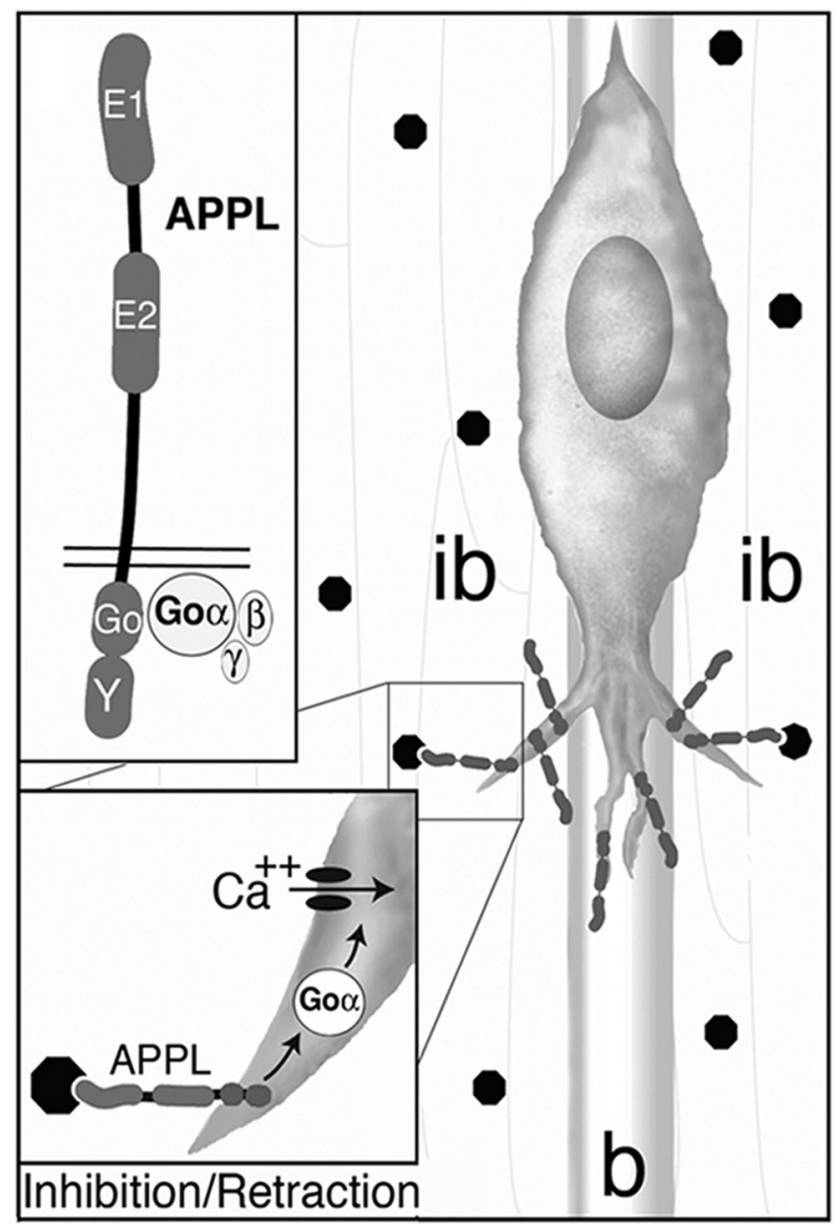

Figure 9. A model for the role of APPL-Go $\alpha$ signaling in the control of neuronal migration within the developing ENS. Transmembrane APPL is expressed in the motile processes of migrating EP cells, where it colocalizes with Go $\alpha$. When exploratory filopodia extend off the band pathway (b) onto the adjacent interband regions (ib), they encounter ligands (as yet unidentified; black octagons) that induce APPL-dependent activation of Go $\alpha$. In turn, local activation of $\mathrm{Go} \alpha$ within the leading process induces $\mathrm{Ca}^{2+}$ influx via voltage-independent channels (Horgan and Copenhaver, 1998), resulting in filopodial retraction, thereby restricting inappropriate outgrowth and migration into these regions.

arborization, and synaptogenesis (Qiu et al., 1995; Torroja et al., 1999a; Leyssen et al., 2005; Soba et al., 2005). In particular, several recent reports have indicated that APP may play an important role in controlling neuronal migration within the mammalian brain. However, different experimental strategies have produced conflicting results, possibly due in part to the overlapping activities of the related proteins APLP1 and APLP2 (Heber et al., 2000). Analogous to the rather subtle defects seen in flies lacking APPL, genetic deletion of APP alone produced no major abnormalities in mouse brain development, although these animals subsequently exhibited a variety of postnatal defects in dendritic growth, synaptic plasticity, and spatial learning (Sugaya et al., 1996; Dawson et al., 1999; Phinney et al., 1999). Even in mice lacking all three APP family proteins, many aspects of brain development were found to be essentially normal, except for a striking pattern of heterotopias resembling cobblestone lissencephaly (Herms et al., 2004), caused by excessive, inappropriate neuronal migration in the developing cortex (Devisme et al., 2012). Similar defects were also reported in mice lacking both Fe65 and Fe65L1 (Guénette et al., 2006), cytoplasmic adapter proteins that regulate APP trafficking and processing and may control the bioavailabil- ity of the holoprotein (McLoughlin and Miller, 2008; Dumanis et al., 2012). These results support the model that signaling by APP and its orthologs normally restricts the extent of neuronal migration, analogous to our results in Manduca. As with APPL in the insect nervous system, we postulate that other guidance cues in addition to APP regulate Go $\alpha$ activity within motile neurons in the developing mammalian brain, providing a mechanism for integrating local growth responses to a variety of environmental stimuli. Given our evidence that endogenously expressed APP and Go $\alpha$ interact in both murine and human neural tissue, it will be interesting to test whether the synaptic defects caused by the loss of APP family proteins can be linked to alterations in Go $\alpha$ dependent signaling pathways.

In contrast to the heterotopias induced by genetic deletion of APP and its orthologs, interfering with APP expression in neuronal precursors by RNA interference resulted in the premature arrest of migration by their progeny (Young-Pearse et al., 2007), suggesting that APP normally promotes migration in response to permissive guidance cues in the developing cortical plate (Young-Pearse et al., 2008; Rice et al., 2012). Recent evidence demonstrating that members of the APP family also regulate the mitotic behavior of cortical progenitors (independent of their role in migration) may provide an explanation for these disparate results (Shariati et al., 2013). Since insect APPL is not expressed by developing neurons until after their terminal mitosis (Luo et al., 1990; Swanson et al., 2005), our manipulations in the embryonic ENS have specifically addressed its function during the migratory period of development.

By exploiting the comparative simplicity of Manduca as a model system, we have shown that APPL plays an important role in regulating the directionality of motile neurons within the nervous system. Knocking down APPL expression in the EP cells with morpholinos eliminated their normal inhibitory response to the interband regions of the ENS, resulting in a distinctive pattern of inappropriate migration and outgrowth (Fig. 8D, G,H). Similarly, treating the migratory neurons with antibodies against the extracellular domain of APPL induced the same ectopic phenotype (Fig. $8 E$ ), presumably by interfering with endogenous interactions between APPL and its functional ligands (as yet unidentified). An alternative explanation is that treatment with anti-APPL antibodies might have accelerated the internalization or clearance of APPL from the surface of the migrating neurons, which would produce the same effect. In comparison, EP cells that remained on the muscle bands in these preparations migrated correctly (Fig. $8 F$ ), indicating that APPL is not required for their response to permissive cues associated with their normal pathways (including Fas II; Wright et al., 1999). Intriguingly, APPL has also been postulated to restrict inappropriate nuclear migration by developing photoreceptor neurons in Drosophila, albeit via a more indirect signaling mechanism (Pramatarova et al., 2006). Whether overstimulation of APPL signaling in the EP cells will induce premature termination of migration (similar to Go $\alpha$ hyperactivation) remains to be determined. Nevertheless, these results support the model that APPL functions as a guidance receptor that transduces neuronal responses to local inhibitory cues, preventing developing neurons from growing into inappropriate regions of the nervous system.

\section{The role of APP-Go $\alpha$ interactions in neural development and disease}

Work on a number of model systems has demonstrated an important role for Go $\alpha$ in the control of neuronal growth and motility. Go $\alpha$ is the most abundant heterotrimeric $\mathrm{G}$ protein in the 
brain (Strathmann and Simon, 1990; Chen et al., 1999); it is enriched in growth cone membranes and migrating neurons (Chang et al., 1988; Strittmatter, 1992; Horgan et al., 1994; Bates and Meyer, 1996), and it regulates neurite outgrowth (He et al., 2006; Bromberg et al., 2008). In cultured chick neurons, PTXsensitive Go/i proteins have been shown to transduce "collapse" responses in growth cones that encounter certain inhibitory cues, in part by promoting $\mathrm{Ca}^{2+}$-dependent filopodial retraction (Igarashi et al., 1993; Nakayama et al., 1999). The misregulation of this pathway may also affect regeneration responses within the mammalian CNS (Bates and Meyer, 1996). Previously, we showed that Go $\alpha$ stimulation in the EP cells inhibits their motility and causes premature stalling within the developing ENS (Fig. $7 C$ ), a response that is transduced via activation of voltageindependent $\mathrm{Ca}^{2+}$ currents (Horgan and Copenhaver, 1998). In contrast, inhibiting Go $\alpha$ resulted in the same characteristic pattern of inappropriate migration and outgrowth caused by interference with APPL-dependent responses (Fig. 8D,E).

Based on our evidence that Go $\alpha$ and APPL colocalize within the leading processes of the EP cells, that they are functionally coupled and directly interact via the Go-binding domain in APPL, and that inhibiting either Go $\alpha$ or APPL signaling produces the same distinctive phenotype of ectopic migration and outgrowth, we hypothesize that APPL functions as a Go $\alpha$-coupled receptor that regulates neuronal motility in a variety of contexts. Moreover, our evidence that transmembrane APP selectively associates with Go $\alpha$ in mammalian neurons (Figs. $2 R-T, 3 H-K$ ) suggests that this interaction is evolutionarily conserved. In the developing nervous system, this signaling pathway would provide a previously unrecognized mechanism for restricting inappropriate migration and outgrowth, a response that might also play a role in synaptic remodeling (complementing the model proposed by Ashley et al., 2005). In the context of $\mathrm{AD}$, several intriguing studies have suggested that the misregulation of APPGo $\alpha$ signaling may also play a role in progressive neurodegeneration. The neurotoxic effects of FAD-associated mutations in APP were previously shown to hyperactivate Go $\alpha$ in cell culture, whereas blocking Go $\alpha$ signaling could prevent the apoptotic effects of disease-associated APP isoforms (Okamoto et al., 1996; Yamatsuji et al., 1996). More recently, studies using human brain samples revealed that both elevated G protein activity and decreased APP-Go $\alpha$ interactions correlated with the severity of AD symptoms (Reis et al., 2007; Shaked et al., 2009; Sola Vigo et al., 2009), while in vitro assays showed that $\mathrm{A} \beta$ peptides could disrupt APP-Go $\alpha$ interactions, resulting in the hyperactivation of Go $\alpha$ and aberrant $\mathrm{Ca}^{2+}$ influx (Reis et al., 2007; Shaked et al., 2009; Sola Vigo et al., 2009). These results are also consistent with evidence that the dysregulation of neuronal $\mathrm{Ca}^{2+}$ may be an important factor in initiating the neurodegenerative responses that typify AD (Khachaturian, 1987; LaFerla, 2002). Further investigation of the normal processes controlled by APP-Go $\alpha$ signaling (including $\mathrm{Ca}^{2+}$-dependent synaptic growth and remodeling) may therefore provide the framework for testing whether the misregulation of this pathway contributes to a variety of agerelated neurological conditions.

\section{References}

Ashley J, Packard M, Ataman B, Budnik V (2005) Fasciclin II signals new synapse formation through amyloid precursor protein and the scaffolding protein dX11/Mint. J Neurosci 25:5943-5955. CrossRef Medline

Banker G, Goslin K (1998) Culturing nerve cells. Cambridge, MA: MIT.

Bates CA, Meyer RL (1996) Heterotrimeric G protein activation rapidly inhibits outgrowth of optic axons from adult and embryonic mouse, and goldfish retinal explants. Brain Res 714:65-75. CrossRef Medline
Benton R, Sachse S, Michnick SW, Vosshall LB (2006) Atypical membrane topology and heteromeric function of Drosophila odorant receptors in vivo. PLoS Biol 4:e20. CrossRef Medline

Bergmans BA, Shariati SA, Habets RL, Verstreken P, Schoonjans L, Müller U, Dotti CG, De Strooper B (2010) Neurons generated from APP/APLP1/ APLP2 triple knockout embryonic stem cells behave normally in vitro and in vivo: lack of evidence for a cell autonomous role of the amyloid precursor protein in neuronal differentiation. Stem Cells 28:399-406. Medline

Bolkan BJ, Triphan T, Kretzschmar D (2012) beta-secretase cleavage of the fly amyloid precursor protein is required for glial survival. J Neurosci 32:16181-16192. CrossRef Medline

Bourne HR, Sanders DA, McCormick F (1991) The GTPase superfamily: conserved structure and molecular mechanisms. Nature 349:117-127. CrossRef Medline

Brand AH, Perrimon N (1993) Targeted gene expression as a means of altering cell fates and generating dominant phenotypes. Development 118: 401-415. Medline

Bromberg KD, Iyengar R, He JC (2008) Regulation of neurite outgrowth by G(i/o) signaling pathways. Front Biosci 13:4544-4557. Medline

Brouillet E, Trembleau A, Galanaud D, Volovitch M, Bouillot C, Valenza C, Prochiantz A, Allinquant B (1999) The amyloid precursor protein interacts with Go heterotrimeric protein within a cell compartment specialized in signal transduction. J Neurosci 19:1717-1727. Medline

Carmine-Simmen K, Proctor T, Tschäpe J, Poeck B, Triphan T, Strauss R, Kretzschmar D (2009) Neurotoxic effects induced by the Drosophila amyloid-beta peptide suggest a conserved toxic function. Neurobiol Dis 33:274-281. CrossRef Medline

Chang KJ, Pugh W, Blanchard SG, McDermed J, Tam JP (1988) Antibody specific to the alpha subunit of the guanine nucleotide-binding regulatory protein Go: developmental appearance and immunocytochemical localization in brain. Proc Natl Acad Sci U S A 85:4929-4933. CrossRef Medline

Chen LT, Gilman AG, Kozasa T (1999) A candidate target for G protein action in brain. J Biol Chem 274:26931-26938. CrossRef Medline

Chen WJ, Goldstein JL, Brown MS (1990) NPXY, a sequence often found in cytoplasmic tails, is required for coated pit-mediated internalization of the low density lipoprotein receptor. J Biol Chem 265:3116-3123. Medline

Clarris HJ, Key B, Beyreuther K, Masters CL, Small DH (1995) Expression of the amyloid protein precursor of Alzheimer's disease in the developing rat olfactory system. Brain Res Dev Brain Res 88:87-95. CrossRef Medline

Coate TM, Swanson TL, Proctor TM, Nighorn AJ, Copenhaver PF (2007) Eph receptor expression defines midline boundaries for ephrin-positive migratory neurons in the enteric nervous system of Manduca sexta. J Comp Neurol 502:175-191. CrossRef Medline

Coate TM, Wirz JA, Copenhaver PF (2008) Reverse signaling via a glycosylphosphatidylinositol-linked ephrin prevents midline crossing by migratory neurons during embryonic development in Manduca. J Neurosci 28:3846-3860. CrossRef Medline

Coate TM, Swanson TL, Copenhaver PF (2009) Reverse signaling by GPIlinked Manduca Ephrin requires a src family kinase to restrict neuronal migration in vivo. J Neurosci 29:3404-3418. CrossRef Medline

Copenhaver PF, Taghert PH (1989a) Development of the enteric nervous system in the moth I. Diversity of cell types and the embryonic expression of FMRFamide-related neuropeptides. Dev Biol 131:70-84. CrossRef Medline

Copenhaver PF, Taghert PH (1989b) Development of the enteric nervous system in the moth II. Stereotyped cell migration precedes the differentiation of embryonic neurons. Dev Biol 131:85-101. CrossRef Medline

Copenhaver PF, Taghert PH (1990) Neurogenesis in the insect enteric nervous system: generation of pre-migratory neurons from an epithelial placode. Development 109:17-28. Medline

Copenhaver PF, Horgan AM, Nichols DC, Rasmussen MA (1995) Developmental expression of heterotrimeric $G$ proteins in the nervous system of Manduca sexta. J Neurobiol 26:461-484. CrossRef Medline

Copenhaver PF, Horgan AM, Combes S (1996) An identified set of visceral muscle bands is essential for the guidance of migratory neurons in the enteric nervous system of Manduca sexta. Dev Biol 179:412-426. CrossRef Medline

Dawson GR, Seabrook GR, Zheng H, Smith DW, Graham S, O'Dowd G, Bowery BJ, Boyce S, Trumbauer ME, Chen HY, Van der Ploeg LH, Sirinathsinghji DJ (1999) Age-related cognitive deficits, impaired long- 
term potentiation and reduction in synaptic marker density in mice lacking the beta-amyloid precursor protein. Neuroscience 90:1-13. CrossRef Medline

Devisme L, Bouchet C, Gonzalès M, Alanio E, Bazin A, Bessières B, Bigi N, Blanchet $\mathrm{P}$, Bonneau $\mathrm{D}$, Bonnières $\mathrm{M}$, Bucourt $\mathrm{M}$, Carles $\mathrm{D}$, Clarisse $\mathrm{B}$, Delahaye S, Fallet-Bianco C, Figarella-Branger D, Gaillard D, Gasser B, Delezoide AL, Guimiot F, et al. (2012) Cobblestone lissencephaly: neuropathological subtypes and correlations with genes of dystroglycanopathies. Brain 135:469-482. CrossRef Medline

Deyts C, Vetrivel KS, Das S, Shepherd YM, Dupr é DJ, Thinakaran G, Parent AT (2012) Novel G $\alpha$ S-protein signaling associated with membranetethered amyloid precursor protein intracellular domain. J Neurosci 32: 1714-1729. CrossRef Medline

Dotti CG, Sullivan CA, Banker GA (1988) The establishment of polarity by hippocampal neurons in culture. J Neurosci 8:1454-1468. Medline

Dumanis SB, Chamberlain KA, Jin Sohn Y, Jin Lee Y, Guénette SY, Suzuki T, Mathews PM, Pak DTs, Rebeck GW, Suh YH, Park HS, Hoe HS (2012) FE65 as a link between VLDLR and APP to regulate their trafficking and processing. Mol Neurodegener 7:9. CrossRef Medline

Frémion F, Astier M, Zaffran S, Guillèn A, Homburger V, Sémériva M (1999) The heterotrimeric protein Go is required for the formation of heart epithelium in Drosophila. J Cell Biol 145:1063-1076. CrossRef Medline

Galés C, Van Durm JJ, Schaak S, Pontier S, Percherancier Y, Audet M, Paris H, Bouvier M (2006) Probing the activation-promoted structural rearrangements in preassembled receptor-G protein complexes. Nat Struct Mol Biol 13:778-786. CrossRef Medline

Gralle M, Ferreira ST (2007) Structure and functions of the human amyloid precursor protein: the whole is more than the sum of its parts. Prog Neurobiol 82:11-32. CrossRef Medline

Guénette S, Chang Y, Hiesberger T, Richardson JA, Eckman CB, Eckman EA, Hammer RE, Herz J (2006) Essential roles for the FE65 amyloid precursor protein-interacting proteins in brain development. EMBO J 25:420-431. CrossRef Medline

Hardy J, Selkoe DJ (2002) The amyloid hypothesis of Alzheimer's disease: progress and problems on the road to therapeutics. Science 297:353-356. CrossRef Medline

Hartenstein V (1988) Development of Drosophila larval sensory organs: spatiotemporal pattern of sensory neurones, peripheral axonal pathways and sensilla differentiation. Development 102:869-886.

He JC, Neves SR, Jordan JD, Iyengar R (2006) Role of the Go/i signaling network in the regulation of neurite outgrowth. Can J Physiol Pharmacol 84:687-694. CrossRef Medline

Heber S, Herms J, Gajic V, Hainfellner J, Aguzzi A, Rülicke T, von Kretzschmar H, von Koch C, Sisodia S, Tremml P, Lipp HP, Wolfer DP, Müller U (2000) Mice with combined gene knock-outs reveal essential and partially redundant functions of amyloid precursor protein family members. J Neurosci 20:7951-7963. Medline

Herms J, Anliker B, Heber S, Ring S, Fuhrmann M, Kretzschmar H, Sisodia S, Müller U (2004) Cortical dysplasia resembling human type 2 lissencephaly in mice lacking all three APP family members. EMBO J 23:41064115. CrossRef Medline

Higashijima T, Burnier J, Ross EM (1990) Regulation of Gi and Go by mastoparan, related amphiphilic peptides, and hydrophobic domains. J Biol Chem 265:14176-14186. Medline

Hiruma K, Riddiford LM (2004) Differential control of MHR3 promoter activity by isoforms of the ecdysone receptor and inhibitory effects of E75A and MHR3. Dev Biol 272:510-521. CrossRef Medline

Ho A, Südhof TC (2004) Binding of F-spondin to amyloid-beta precursor protein: a candidate amyloid-beta precursor protein ligand that modulates amyloid-beta precursor protein cleavage. Proc Natl Acad Sci U S A 101:2548-2553. CrossRef Medline

Hoe HS, Rebeck GW (2008) Functional interactions of APP with the apoE receptor family. J Neurochem 106:2263-2271. CrossRef Medline

Horgan AM, Copenhaver PF (1998) G protein-mediated inhibition of neuronal migration requires calcium influx. J Neurosci 18:4189-4200. Medline

Horgan AM, Lagrange MT, Copenhaver PF (1994) Developmental expression of $\mathrm{G}$ proteins in a migratory population of embryonic neurons. Development 120:729-742. Medline

Horgan AM, Lagrange MT, Copenhaver PF (1995) A developmental role for the heterotrimeric $\mathrm{G}$ protein $\mathrm{Go}_{\alpha}$ in a migratory population of embryonic neurons. Dev Biol 172:640-653. CrossRef Medline
Hortsch M (1994) Preparation and analysis of membranes and membrane proteins from Drosophila. Methods Cell Biol 44:289-301. CrossRef Medline

Igarashi M, Strittmatter SM, Vartanian T, Fishman MC (1993) Mediation by $\mathrm{G}$ proteins of signals that cause collapse of growth cones. Science 259:77-79. CrossRef Medline

Karran E, Mercken M, De Strooper B (2011) The amyloid cascade hypothesis for Alzheimer's disease: an appraisal for the development of therapeutics. Nat Rev Drug Discov 10:698-712. CrossRef Medline

Kerppola TK (2008) Bimolecular fluorescence complementation (BiFC) analysis as a probe of protein interactions in living cells. Annual review of biophysics 37:465-487. CrossRef Medline

Khachaturian ZS (1987) Hypothesis on the regulation of cytosol calcium concentration and the aging brain. Neurobiol Aging 8:345-346. CrossRef Medline

LaFerla FM (2002) Calcium dyshomeostasis and intracellular signalling in Alzheimer's disease. Nat Rev Neurosci 3:862-872. CrossRef Medline

Leyssen M, Ayaz D, Hébert SS, Reeve S, De Strooper B, Hassan BA (2005) Amyloid precursor protein promotes post-developmental neurite arborization in the Drosophila brain. EMBO J 24:2944-2955. CrossRef Medline

Luo LQ, Martin-Morris LE, White K (1990) Identification, secretion, and neural expression of APPL, a Drosophila protein similar to human amyloid protein precursor. J Neurosci 10:3849-3861. Medline

Luo L, Tully T, White K (1992) Human amyloid precursor protein ameliorates behavioral deficit of flies deleted for Appl gene. Neuron 9:595-605. CrossRef Medline

Mangialasche F, Solomon A, Winblad B, Mecocci P, Kivipelto M (2010) Alzheimer's disease: clinical trials and drug development. Lancet Neurol 9:702-716. CrossRef Medline

Mangmool S, Kurose H (2011) G(i/o) Protein-Dependent and -Independent Actions of Pertussis Toxin (PTX). Toxins 3:884-899. CrossRef Medline

Martin-Morris LE, White K (1990) The Drosophila transcript encoded by the beta-amyloid protein precursor-like gene is restricted to the nervous system. Development 110:185-195. Medline

McLoughlin DM, Miller CC (2008) The FE65 proteins and Alzheimer's disease. J Neurosci Res 86:744-754. CrossRef Medline

Mervine SM, Yost EA, Sabo JL, Hynes TR, Berlot CH (2006) Analysis of G protein betagamma dimer formation in live cells using multicolor bimolecular fluorescence complementation demonstrates preferences of beta 1 for particular gamma subunits. Mol Pharmacol 70:194-205. Medline

Mora N, Almudi I, Alsina B, Corominas M, Serras F (2013) beta amyloid protein precursor-like (Appl) is a Ras1/MAPK-regulated gene required for axonal targeting in Drosophila photoreceptor neurons. J Cell Sci 126: 53-59. CrossRef Medline

Muresan V, Varvel NH, Lamb BT, Muresan Z (2009) The cleavage products of amyloid-beta precursor protein are sorted to distinct carrier vesicles that are independently transported within neurites. J Neurosci 29:3565-3578. CrossRef Medline

Nakayama T, Goshima Y, Misu Y, Kato T (1999) Role of cdk5 and tau phosphorylation in heterotrimeric $\mathrm{G}$ protein-mediated retinal growth cone collapse. J Neurobiol 41:326-339. CrossRef Medline

Nishimoto I, Okamoto T, Matsuura Y, Takahashi S, Okamoto T, Murayama Y, Ogata E (1993) Alzheimer amyloid protein precursor complexes with brain GTP-binding protein Go. Nature 362:75-79. CrossRef Medline

Okamoto T, Katada T, Murayama Y, Ui M, Ogata E, Nishimoto I (1990) A simple structure encodes G protein-activating function of the IGF-II/ mannose 6-phosphate receptor. Cell 62:709-717. CrossRef Medline

Okamoto T, Takeda S, Murayama Y, Ogata E, Nishimoto I (1995) Liganddependent $\mathrm{G}$ protein coupling function of amyloid transmembrane precursor. J Biol Chem 270:4205-4208. CrossRef Medline

Okamoto T, Takeda S, Giambarella U, Murayama Y, Matsui T, Katada T, Matsuura Y, Nishimoto I (1996) Intrinsic signaling function of APP as a novel target of three V642 mutations linked to familial Alzheimer's disease. EMBO J 15:3769-3777. Medline

Osterfield M, Egelund R, Young LM, Flanagan JG (2008) Interaction of amyloid precursor protein with contactins and $\mathrm{NgCAM}$ in the retinotectal system. Development 135:1189-1199. CrossRef Medline

Patel TB (2004) Single transmembrane spanning heterotrimeric G protein-coupled receptors and their signaling cascades. Pharmacol Rev 56:371-385. CrossRef Medline

Perez RG, Zheng H, Van der Ploeg LH, Koo EH (1997) The beta-amyloid 
precursor protein of Alzheimer's disease enhances neuron viability and modulates neuronal polarity. J Neurosci 17:9407-9414. Medline

Phinney AL, Calhoun ME, Wolfer DP, Lipp HP, Zheng H, Jucker M (1999) No hippocampal neuron or synaptic bouton loss in learningimpaired aged beta-amyloid precursor protein-null mice. Neuroscience 90:1207-1216. CrossRef Medline

Pramatarova A, Ochalski PG, Lee CH, Howell BW (2006) Mouse disabled 1 regulates the nuclear position of neurons in a Drosophila eye model. Mol Cell Biol 26:1510-1517. CrossRef Medline

Qiu WQ, Ferreira A, Miller C, Koo EH, Selkoe DJ (1995) Cell-surface betaamyloid precursor protein stimulates neurite outgrowth of hippocampal neurons in an isoform-dependent manner. J Neurosci 15:2157-2167. Medline

Reinhard C, Hébert SS, De Strooper B (2005) The amyloid-beta precursor protein: integrating structure with biological function. EMBO J 24:39964006. CrossRef Medline

Reis K, Zharkovsky A, Bogdanovic N, Karelson E, Land T (2007) Critical role of methionine-722 in the stimulation of human brain G-proteins and neurotoxicity induced by London familial Alzheimer's disease (FAD) mutated V717G-APP(714-723). Neuroscience 144:571-578. CrossRef Medline

Remy I, Montmarquette A, Michnick SW (2004) PKB/Akt modulates TGFbeta signalling through a direct interaction with Smad3. Nat Cell Biol 6:358-365. CrossRef Medline

Rice HC, Townsend M, Bai J, Suth S, Cavanaugh W, Selkoe DJ, Young-Pearse TL (2012) Pancortins interact with amyloid precursor protein and modulate cortical cell migration. Development 139:3986-3996. CrossRef Medline

Robida AM, Kerppola TK (2009) Bimolecular fluorescence complementation analysis of inducible protein interactions: effects of factors affecting protein folding on fluorescent protein fragment association. J Mol Biol 394:391-409. CrossRef Medline

Sabo SL, Ikin AF, Buxbaum JD, Greengard P (2003) The amyloid precursor protein and its regulatory protein, FE65, in growth cones and synapses in vitro and in vivo. J Neurosci 23:5407-5415. Medline

Shaked GM, Chauv S, Ubhi K, Hansen LA, Masliah E (2009) Interactions between the amyloid precursor protein C-terminal domain and G proteins mediate calcium dysregulation and amyloid beta toxicity in Alzheimer's disease. FEBS J 276:2736-2751. CrossRef Medline

Shariati SA, Lau P, Hassan BA, Müller U, Dotti CG, De Strooper B, Gärtner A (2013) APLP2 regulates neuronal stem cell differentiation during cortical development. J Cell Sci 126:1268-1277. CrossRef Medline

Soba P, Eggert S, Wagner K, Zentgraf H, Siehl K, Kreger S, Löwer A, Langer A, Merdes G, Paro R, Masters CL, Müller U, Kins S, Beyreuther K (2005) Homo- and heterodimerization of APP family members promotes intercellular adhesion. EMBO J 24:3624-3634. CrossRef Medline

Sola Vigo F, Kedikian G, Heredia L, Heredia F, Añel AD, Rosa AL, Lorenzo A (2009) Amyloid-beta precursor protein mediates neuronal toxicity of amyloid beta through Go protein activation. Neurobiol Aging 30: 1379-1392. CrossRef Medline

Sprecher SG, Cardona A, Hartenstein V (2011) The Drosophila larval visual system: high-resolution analysis of a simple visual neuropil. Dev Biol 358:33-43. CrossRef Medline

Steller H, Fischbach KF, Rubin GM (1987) Disconnected: a locus required for neuronal pathway formation in the visual system of Drosophila. Cell 50:1139-1153. CrossRef Medline

Sternweis PC, Gilman AG (1982) Aluminum: a requirement for activation of the regulatory component of adenylate cyclase by fluoride. Proc Natl Acad Sci U S A 79:4888-4891. CrossRef Medline

Strathmann M, Simon MI (1990) G protein diversity: a distinct class of $\alpha$-subunits is present in vertebrates and invertebrates. Proc Natl Acad Sci U S A 87:9113-9117. CrossRef Medline

Strittmatter SM (1992) GAP-43 as a modulator of G protein transduction in the growth cone. Perspect Dev Neurobiol 1:13-19. Medline

Stryer L, Bourne HR (1986) G proteins: a family of signal transducers. Annu Rev Cell Biol 2:391-419. CrossRef Medline

Sugaya K, Chouinard M, Greene R, Robbins M, Personett D, Kent C, Gallagher M, McKinney M (1996) Molecular indices of neuronal and glial plasticity in the hippocampal formation in a rodent model of age-induced spatial learning impairment. J Neurosci 16:3427-3443. Medline

Swanson TL, Knittel LM, Coate TM, Farley SM, Snyder MA, Copenhaver PF (2005) The insect homologue of the amyloid precursor protein interacts with the heterotrimeric $\mathrm{G}$ protein Go alpha in an identified population of migratory neurons. Dev Biol 288:160-178. CrossRef Medline

Thambi NC, Quan F, Wolfgang WJ, Spiegel A, Forte M (1989) Immunological and molecular characterization of $\mathrm{Go}_{\alpha}$-like proteins in the Drosophila CNS. J Biol Chem 264:18552-18560. Medline

Timossi C, Ortiz-Elizondo C, Pineda DB, Dias JA, Conn PM, Ulloa-Aguirre A (2004) Functional significance of the BBXXB motif reversed present in the cytoplasmic domains of the human follicle-stimulating hormone receptor. Mol Cell Endocrinol 223:17-26. CrossRef Medline

Tix S, Minden JS, Technau GM (1989) Pre-existing neuronal pathways in the developing optic lobes of Drosophila. Development 105:739-746. Medline

Torroja L, Chu H, Kotovsky I, White K (1999a) Neuronal overexpression of APPL, the Drosophila homologue of the amyloid precursor protein (APP), disrupts axonal transport. Curr Biol 9:489-492. CrossRef Medline

Torroja L, Packard M, Gorczyca M, White K, Budnik V (1999b) The Drosophila beta-amyloid precursor protein homolog promotes synapse differentiation at the neuromuscular junction. J Neurosci 19:7793-7803. Medline

Turner PR, O'Connor K, Tate WP, Abraham WC (2003) Roles of amyloid precursor protein and its fragments in regulating neural activity, plasticity and memory. Prog Neurobiol 70:1-32. CrossRef Medline

Wentzell JS, Bolkan BJ, Carmine-Simmen K, Swanson TL, Musashe DT, Kretzschmar D (2012) Amyloid precursor proteins are protective in Drosophila models of progressive neurodegeneration. Neurobiol Dis 46: 78-87. CrossRef Medline

Wright JW, Schwinof KM, Snyder MA, Copenhaver PF (1998) A delayed role for nitric oxide-sensitive guanylate cyclases in a migratory population of embryonic neurons. Dev Biol 203:15-33.

Wright JW, Snyder MA, Schwinof KM, Combes S, Copenhaver PF (1999) A role for fasciclin II in the guidance of neuronal migration. Development 126:3217-3228. Medline

Wu D, Jiang H, Simon MI (1995) Different alpha 1-adrenergic receptor sequences required for activating different $\mathrm{G}$ alpha subunits of $\mathrm{Gq}$ class of G proteins. J Biol Chem 270:9828-9832. CrossRef Medline

Yamatsuji T, Matsui T, Okamoto T, Komatsuzaki K, Takeda S, Fukumoto H, Iwatsubo T, Suzuki N, Asami-Odaka A, Ireland S, Kinane TB, Giambarella U, Nishimoto I (1996) G protein-mediated neuronal DNA fragmentation induced by familial Alzheimer's disease-associated mutants of APP. Science 272:1349-1352. CrossRef Medline

Young-Pearse TL, Bai J, Chang R, Zheng JB, LoTurco JJ, Selkoe DJ (2007) A critical function for beta-amyloid precursor protein in neuronal migration revealed by in utero RNA interference. J Neurosci 27:14459-14469. CrossRef Medline

Young-Pearse TL, Chen AC, Chang R, Marquez C, Selkoe DJ (2008) Secreted APP regulates the function of full-length APP in neurite outgrowth through interaction with integrin betal. Neural Dev 3:15. CrossRef Medline 